\title{
Wild edible plants: Nutritional and toxicological characteristics, retrieval strategies and importance for today's society
}

\author{
José Pinela, Ana Maria Carvalho, Isabel C.F.R. Ferreira* \\ Centro de Investigação de Montanha (CIMO), Instituto Politécnico de Bragança, Campus de Santa Apolónia, 5300-253 Bragança, Portugal
}

\section{A R T I C L E I N F O}

\section{Keywords:}

Wild edible

Functional foods

Valorisation

Nutritional composition

Bioactive compounds

Food safety

\begin{abstract}
A B S T R A C T
Wild edible plants (WEPs) are part of the cultural and genetic heritage of different regions of the world. In times of famine and scarcity, these sources of nutrients and health-promoting compounds have received high importance mainly in rural and suburban areas. Although currently underutilized, WEPs are still consumed traditionally by different communities and are gaining relevance in today's society. However, these foods lack recognition as significant contributors to the human diet in developed areas. This review describes the nutritional value of WEPs from the North-eastern region of Portugal and points out those containing potentially toxic compounds. Several retrieval strategies are presented with the aim of promoting the (re)use, production, commercialization and conservation of WEPs (wild harvested plants and crop wild relatives), and their importance for social, economic and agro-ecological development is highlighted.
\end{abstract}

\section{Introduction}

Wild plants have received great importance at different places and times of the human history given their ability to provide nutrients during scarcity periods and protection for minor health conditions (Torija-Isasa and Matallana-González, 2016). Their popularity comes from the need for nourishment in regions experiencing food shortages, where wild edible plants (WEPs) have played an important role in complementing staple agricultural foods and poverty alleviation, and from the perceived health-promoting effects and cultural trends (Sõukand, 2016). Moreover, the long use of WEPs is associated with particular wisdom and practices, and above all great creativity pulsing with life, and with each user, household, region or country.

The current underutilization of WEPs was promoted by industrial revolution, lifestyle changes, large-scale cultivation of a limited number of crops (such as wheat, maize and rice), and less contact with nature, among other reasons (Łuczaj et al., 2012). In fact, in developed countries, cultivated plant-based foods purchased at the supermarket are placed on the table with relatively less effort than if collected from the wild. Nevertheless, many people around the world continue to rely on WEPs to meet at least part of their daily nutritional needs (Turner et al., 2011). Moreover, a new phenomenon associated with the use of WEPs is emerging in modern societies (Carvalho and Barata, 2016).

Several studies carried out in the last years revealed the important role of WEPs as sources of nutrients and contributors to human dietary requirements (Sánchez-Mata et al., 2016). Some WEPs have also been described as being functional foods, because they contain physiologically active ingredients capable of providing health benefits beyond basic nutrition (Pinela et al., 2016e); while others may contain potentially toxic compounds to humans (EFSA, 2012, 2009). Therefore, this article reviews the nutritional composition of WEPs from the Northeastern region of Portugal and safety issues related to their use. These species were selected based on ethnobotanical data that have recalled from memory such traditional knowledge and practices regarding the use of WEPs (Carvalho, 2010; Carvalho and Morales, 2010; Tardío et al., 2006; Tuttolomondo et al., 2014). Strategies for retrieval of these species are also herein discussed, highlighting their importance for today's society. Moreover, these approaches might contribute to local sustainable development and innovative options for rural and marginalized areas, meeting the main goals of United Nations, such as promote inclusive and sustainable socioeconomic growth and provide wellbeing and healthy lives for all (European Commission, 2016).

\section{Wild edible plants from North-eastern Portugal}

WEPs traditionally consumed in the North-eastern region of Portugal are presented in Table 1. Species belonging to 17 families including Asteraceae, Lamiaceae, Polygonaceae, Amaranthaceae, Apiaceae, Boraginaceae, Portulacaceae, Asparagaceae, Cannabaceae, Caryophyllaceae, Dioscoreaceae, Malvaceae, and Papaveraceae were reviewed, as well as others of economically important botanical families or locally highly prized such as Brassicaceae, Cucurbitaceae,

\footnotetext{
* Corresponding author.

E-mail address: iferreira@ipb.pt (I.C.F.R. Ferreira).
} 


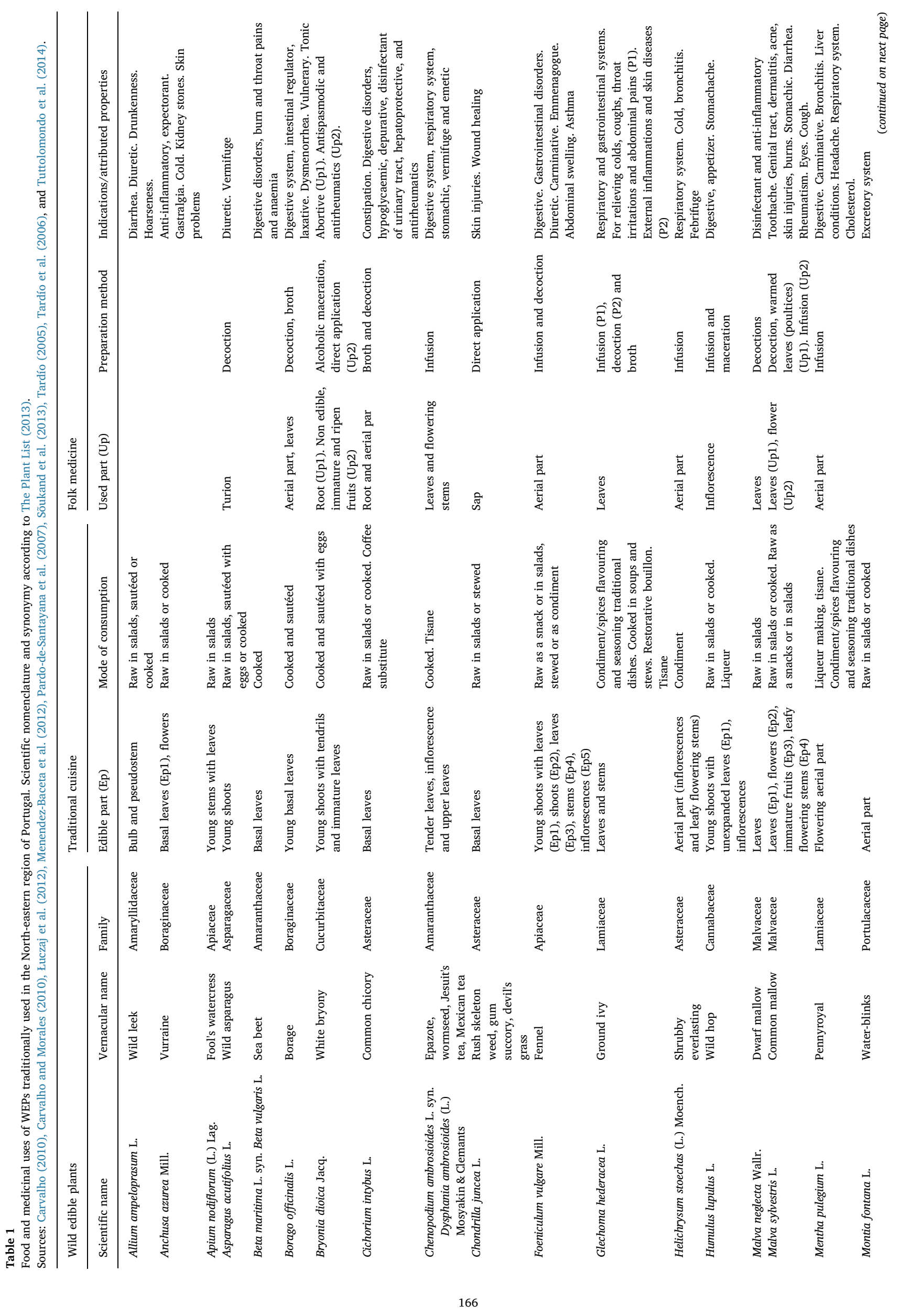




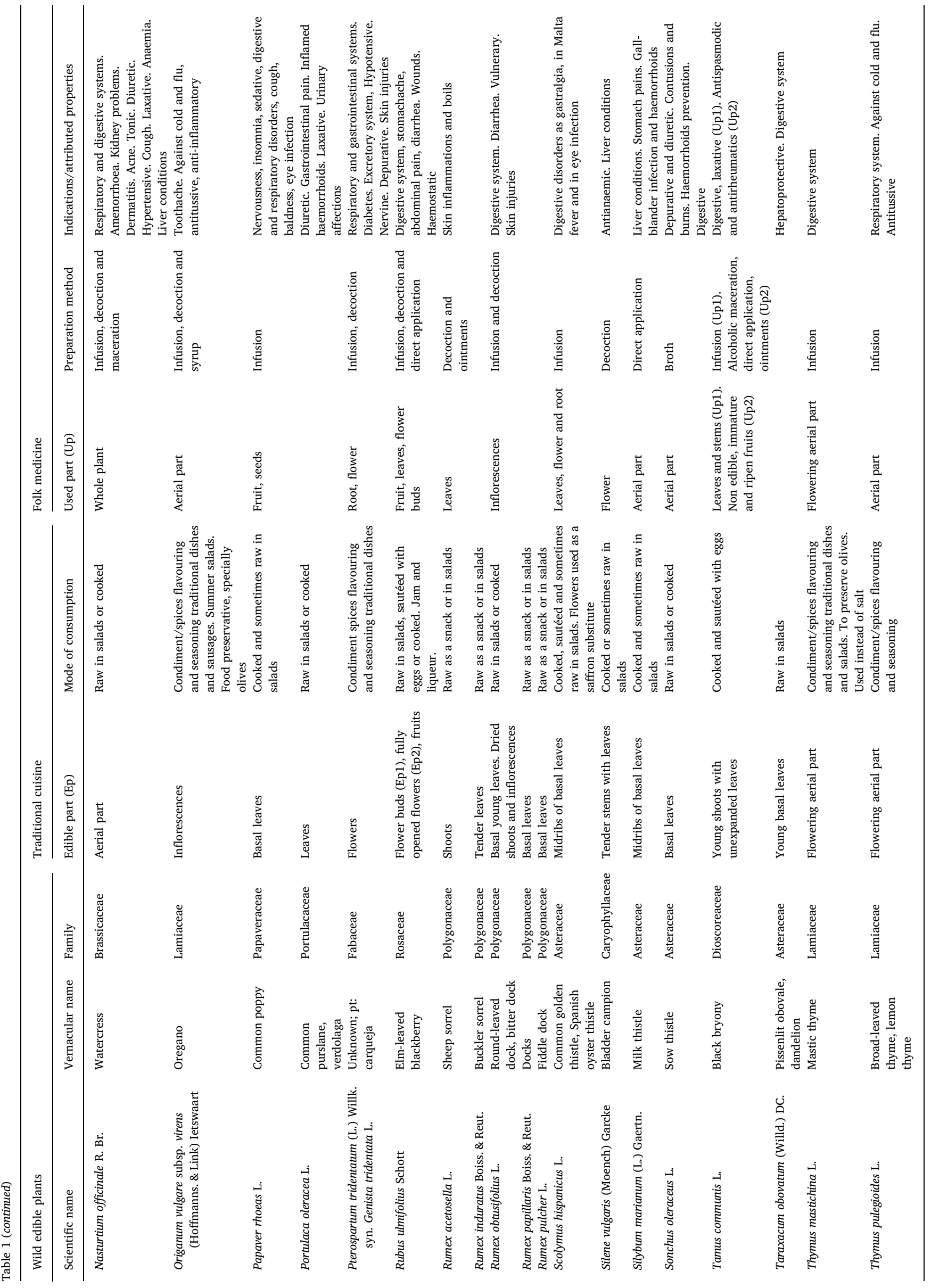



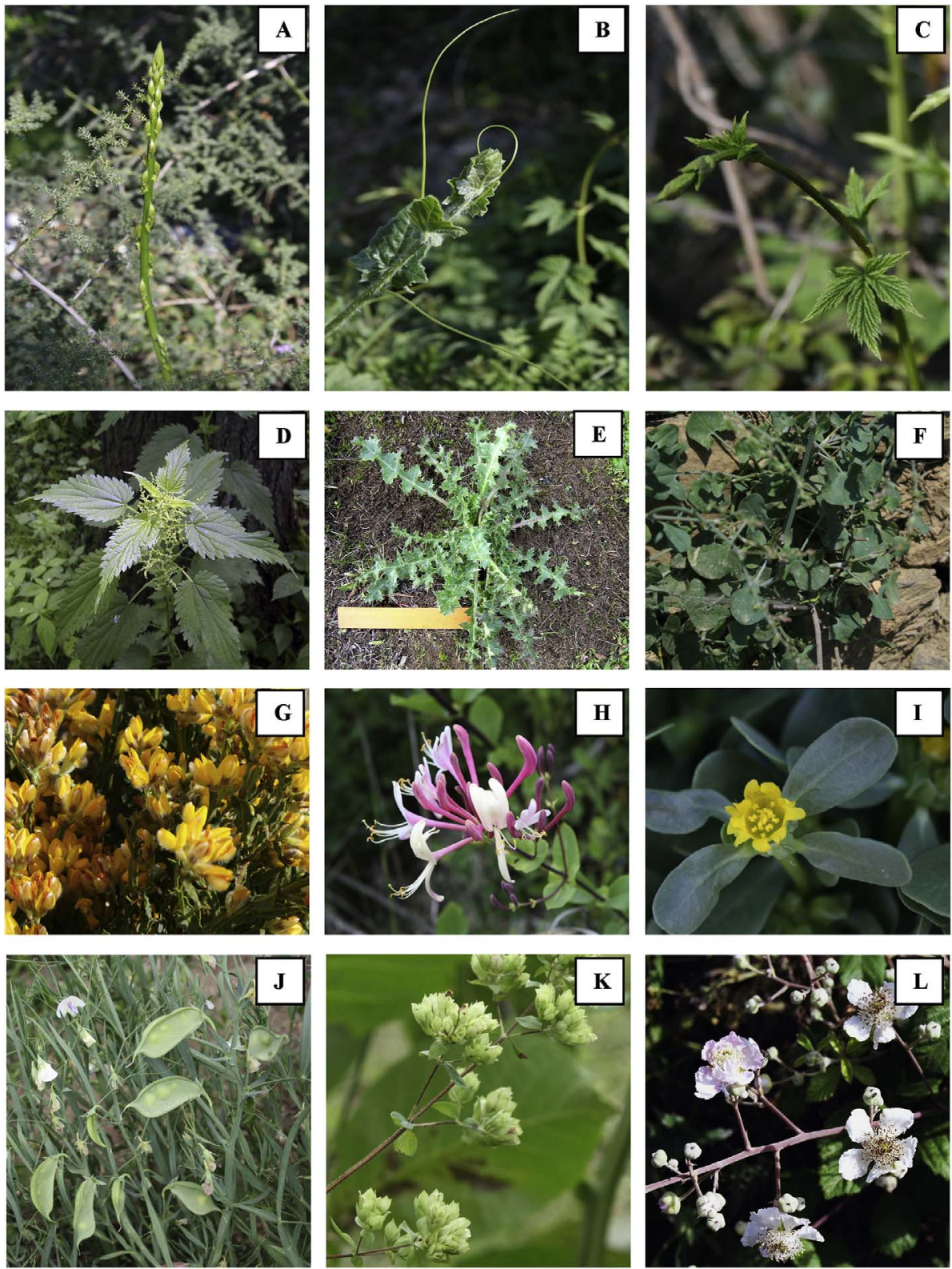

Fig. 1. Some examples of wild species and plant materials traditionally used in the North-eastern region of Portugal as food and/or medicine. A: Asparagus acutifolius L.; B: Bryonia dioica Jacq.; C: Humulus lupulus L.; D: Urtica dioica L.; E: Scolymus hispanicus L.; F: Rumex induratus Boiss. \& Reut.; G: Genista tridentata L.; H: Lonicera etrusca Santi; I: Portulaca oleracea L.; J: Lathyrus sativus L.; K: Origanum vulgare L.; and L: Rubus ulmifolius Schott. Nomenclature according to The Plant List (2013).
Fabaceae, and Rosaceae. These species are usually gathered and consumed as wild vegetables, spices/condiments, snacks, recreational beverages and fruits, but are also prepared in medicinal infusions and decoctions for the treatment and prevention of various diseases and health conditions. Most of the times, these WEPs are collected from the wild where they grow spontaneously; but some wild forms are occasionally brought to the garden and cultivated directly for food purposes, such as Origanum vulgare L., Scolymus hispanicus L. (Fig. 1), Silene vulgaris (Moench) Garcke and Rumex sp. pl., with the aim of obtaining a higher yield, an immediate availability, and overcome a possible lack of such species in the region.

\subsection{Wild plants as sustainable foods}

Wild vegetables have been the mainstay of human diets for centuries and people still continue reserving some time for collecting these foods, which are rich in micronutrients and highly appreciated raw in salads or cooked in traditional recipes. As shown in Table 1, the edible parts harvested and consumed are different depending on species and growth stage. Some examples of the most common plant parts used are basal leaves (including the ones of Sonchus oleraceus L., Papaver rhoeas L., Cichorium intybus L., Chondrilla juncea L., Beta maritima L., Rumex papillaris Boiss. \& Reut., Rumex pulcher L. and Anchusa azurea Mill.), or just the midribs (as in the case of Scolymus hispanicus L. and Silybum marianum (L.) Gaertn.), young stems with leaves (like the four widespread species of wild asparagus Asparagus acutifolius L., Bryonia dioica Jacq., Humulus lupulus L. and Tamus communis L.; Fig. 1), and other organs such as the edible bulb and pseudostem (lower part of the leaves) of Allium ampeloprasum L. (wild leek). These vegetables are consumed both raw and cooked, although others are more often eaten cooked (such as Rumex species, Borago officinalis L. and Silene vulgaris).

In times of scarcity, some WEPs were eaten in the field as snacks without any preparation, or chewed and spitted for entertainment, as hunger or thirst quencher, or to enjoy its flavour. These snacks consisted mostly of flowers that were sucked because of the sweet taste of the nectar (e.g., Malva sylvestris L. and Lamium purpureum L.), but also in the tasty and interesting-looking immature fruits of Fabaceae such as Astragalus and Vicia species, Foeniculum vulgare Mill., Malva sylvestris and Capsella bursa-pastoris (L.) Medik. (Carvalho, 2010; Tardío, 2005; Tardío et al., 2006). The peeled young shoots of Rubus ulmifolius Schott, 
as well as of wild roses and young shoots and leaves of Rumex sp.pl, were eaten raw in spring. Foeniculum vulgare was used as thirst quencher or breath refreshment (Tardio et al., 2002). These snacks were eaten occasionally (mostly by children and shepherds) and not as regular food, although some nutritional value was perceived (MenendezBaceta et al., 2012).

Aromatic plants are very important in the gastronomy of the Northeastern Portugal. Flowering parts of Foeniculum vulgare Origanum vulgare, Mentha pulegium L., Thymus pulegioides L., Thymus mastichina L., Genista tridentata L. (syn. Pterospartum tridentatum (L.) Willk.; Fig. 1), Helichrysum stoechas (L.) Moench. and Glechoma hederacea L. are traditionally used as condiments/spices for flavouring and seasoning of traditional dishes and salads (Table 1). T. mastichina is also used as a salt substitute and olives preservative. Some of these aromatic plant were used for seasoning soups and purees in order to diversify the monotonous diet (Carvalho and Morales, 2010; Pardo-de-Santayana et al., 2007).

Other WEPs were prepared in recreational beverages, both alcoholic and non-alcoholic, such as tisanes (herbal teas) and liqueurs. These herbal teas are consumed in a food context for their social and/or recreational value or their attributes of healthy drinks, not including infusions/decoctions taken only for specific medicinal purposes (Sõukand et al., 2013). While medicinal beverages are purposely taken for a limited number of days to treat a certain health condition, there is no limit to the duration that recreational teas can be consumed. In addition, herbal teas are drunk hot or cold according to the season. As shown in Table 1, M. pulegium, G. hederacea and Dysphania ambrosioides (L.) Mosyakin \& Clemants (syn. Chenopodium ambrosioides L.) were prepared in tisanes. In turn, M. pulegium and Humulus lupulus inflorescences and the fruits of Rubus ulmifolius and Prunus spinosa L. were used to make liqueurs (Carvalho, 2010; Menendez-Baceta et al., 2012).

\subsection{Wild plants as folk medicines}

The majority of the species presented in Table 1 were perceived as having medicinal properties. They were used in local folk medicine, prepared mainly in medicinal infusions and decoctions to treat several health conditions, but also in macerations, syrups, poultices, broths, or applied directly. Medicinal beverages were taken to treat mainly digestive disorders (such as those prepared from Beta maritima, Thymus mastichina, Borago officinalis, Rubus ulmifolius, Humulus lupulus and Foeniculum vulgare) and respiratory system problems (including the ones prepared from Mentha pulegium, Genista tridentata, Helichrysum stoechas and Papaver rhoeas). Others were used for their disinfectant or anti-inflammatory effects (namely Origanum vulgare, Anchusa azurea, Chichorium intybus, Glecoma hederacea and Rumex acetosella L.). Liver conditions, urinary affections, skin problems, toothache, diabetes, cold, flu and bronchitis, among other problems, were also treated using WEPs (Table 1). However, the traditional knowledge and local healers assume that the oral preparations from some of these plants can lead to some risks, especially due to excessive doses and long-term treatments, thus recommending specific dosages and controlled periods of intake with ritual healing practices (Carvalho, 2010).

Other examples of edible species with medicinal applications are as follows: the fruits of Bryonia dioica and Tammus communis used to be macerated in alcohol or crushed and applied topically as an ointment to treat rheumatic and muscular pains. The sap of Chondrilla juncea was applied to treat and heal skin injuries. Dermatitis, burns and skin injuries were also treated with warmed leaves of Malva sylvestris as poultices. Syrup against cold and flu used to be prepared from Origanum vulgare aerial parts. Borago officinalis, Cichorium intybus and Sonchus oleraceus were also consumed in medicinal broths.

\subsection{Crop wild relatives and landrace diversity}

Crop wild relatives are wild plant species closely related to cultivated plants (Maxted et al., 2006). These species are components of both natural habitats and agro-ecosystems and constitute an important element of plant genetic heritage that needs to be conserved (Castañeda-Álvarez et al., 2016). An inventory performed by Magos Brehm et al. (2008) reported the existence of 2262 taxa (including subspecies and varieties) of crop wild relatives in the Portuguese flora, representing $\sim 9.6 \%$ of the European and Mediterranean crop wild relatives flora. Examples of crop wild relatives that used to be eaten in north-eastern Portugal include:

- In the Fabaceae family: The immature pods of wild pea (Lathyrus cicera L.), flat pea (Lathyrus sylvestris L.), milkvetches (Astragalus cymbaecarpos Brot. and A. pelecinus (L.) Barneby), narrow-leaved vetch (Vicia angustifolia L.), hairy vetch (Vicia villosa Roth) and yellow vetch (Vicia lutea L.) were eaten raw. Single-flower vetch (Vicia articulata Hornem.) seeds were consumed due to its resemblance with those of small-seeded lentil cultivars.

- In the Brassicaceae family: Wild arugula (Eruca vesicaria (L.) Cav.), garlic mustard (Alliaria petiolata (M. Bieb.) Cavara \& Grande), white wall-rocket (Diplotaxis erucoides (L.) DC.), wild mustard (Sinapis arvenses $\mathrm{L}$.), wild watercress (Nasturtium officinale $\mathrm{R}$. Br.) and white mustard (Sinapis alba L.). Their basal leaves and young shoots were eaten raw in salads or cooked and consumed as greens or in soups. The seeds of white mustard were used as a mild flavour for pickling or grilled meat.

- In the Rosaceae family: Wild strawberry (Fragaria vesca L.), common hawthorn (Crataegus monogyna Jacq.), blackthorn (Prunus spinosa L.), European crab apple (Malus sylvestris (L.) Mill.) and elm-leaved blackberry (Rubus ulmifolius) (Fig. 1). From all these species the bletted fruits, that are sweeter, were eaten raw as snacks. When ripen they were also cooked to be edible and used to prepare marmalades. The young shoots (pointed ends) of elm-leaved blackberry were consume like asparagus and served as a garnish.

- In the Asteraceae family: Wild lettuces (Lactuca serriola L., L. virosa L., and Taraxacum species). Basal leaves were used raw in salads.

- In the Apiaceae family: Wild carrots (Daucus carota L.) and Angelica sylvestris L. and A. major Lag.. D. carota tuberous root is edible while young and was consumed either raw or cooked. The leaves, tender shoots and stems of Angelica species were prepared as vegetables. Sometimes could be boiled to a stew. They were also used raw, as an aromatic addition to salads.

Some of these wild foods (e.g. the edible fruits of the four Rosaceae species $C$. monogyna, $P$. spinosa, $R$. ulmifolius and $F$. vesca) have been already characterized in terms of nutrients and bioactive properties in order to highlight their potential for human nutrition (Barros et al., 2010c; Dias et al., 2016; Morales et al., 2013). However, despite the importance of these crops' wild relatives, this review is focused on the wild harvested plants presented in Table 1.

\section{Nutritional composition}

The nutritional composition of the selected WEPs is discussed below, as well as its contribution to the recommended dietary allowances (RDA) of certain nutrients for male and female adults (31 through 50 years), i.e. the average daily dietary intake level that is sufficient to meet the nutrient requirements of nearly all healthy individuals in this age-specific group (Otten et al., 2006). Additionally, a plant part was considered as a source of a certain nutrient when a 100-g portion contributes to more than $15 \%$ for the RDA and as having a high content when the same 100-g portion contributes in more than $30 \%$ (Table A1).

\subsection{Proximate composition}

The proximate composition comprising the major nutritional value indicators and the energetic value of the selected WEPs is presented in Table 2. The midribs of basal leaves of Silybum marianum, the aerial 


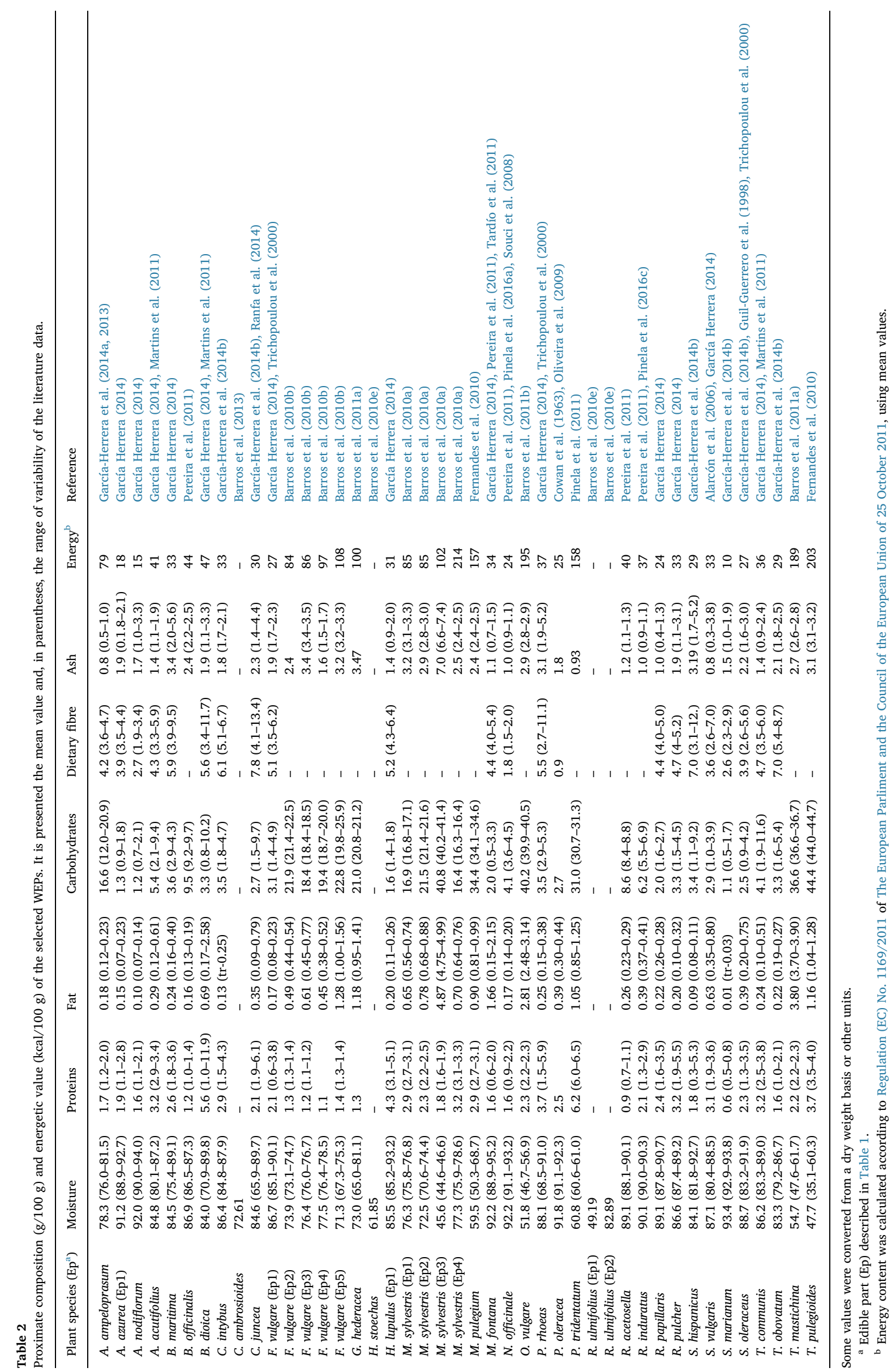


parts of the semi-aquatic plants Montia fontana L. and Nasturtium officinale, the young stems with leaves of Apium nodiflorum (L.) Lag. and the leaves of Portulaca oleracea L. have the highest moisture content (ranging from 91.8 to $93.4 \mathrm{~g} / 100 \mathrm{~g}$ ) (Cowan et al., 1963; GarcíaHerrera et al., 2014b; García Herrera, 2014; Oliveira et al., 2009; Pereira et al., 2011; Pinela et al., 2016a; Tardío et al., 2011). These plants are usually consumed raw in salads, sautéed or cooked (Table 1). In turn, the immature fruits of M. sylvestris (Barros et al., 2010a) and plants used as a condiment or spice (mainly flowering parts) reveal the lowest moisture content $(<62 \mathrm{~g} / 100 \mathrm{~g})$. This is the case of Thymus pulegioides, T. mastichina, Mentha pulegium, Origanum vulgare, Pterospartum tridentatum and Helichrysum stoechas (Barros et al., 2011a, 2010e; Fernandes et al., 2010; Pinela et al., 2011).

The protein levels of the selected WEPs range from 0.6 to $6.2 \mathrm{~g} /$ $100 \mathrm{~g}$ (Table 2). The flowers of $P$. tridentatum (Pinela et al., 2011) and the young aerial parts of Bryonia dioica (Fig. 1) (García Herrera, 2014; Martins et al., 2011) present the highest amounts. However, a 100-g portion of these plants only contributes in $11.1 / 13.5$ and $10.0 / 12.2 \%$ for the RDA for male/female adults, respectively (Table A1). Thus, the selected edible plants are not good sources of proteins. These gross constituents are generally calculated based on the amount of total Kjeldahl nitrogen that is multiplied by the conversion factor 6.25 (AOAC, 2016; Regulation (EU) No 1169/2011).

The fat levels are $\leq 4.87 \mathrm{~g} / 100 \mathrm{~g}$ and the higher amounts are presented by the immature fruits of M. sylvestris (Barros et al., 2010a) and the flowering aerial parts of the aromatic plants T. mastichina and $O$. vulgare (Barros et al., 2011a). Taking into consideration the reference intake of $70 \mathrm{~g} /$ day for total fat for adults (Regulation (EU) No 1169/ 2011), it can be concluded that all selected plants are low-fat foods (contributions $\leq 7 \%$ ).

The immature fruits of $M$. sylvestris and the flowering aerial parts of T. pulegioides and $O$. vulgare were those to present the highest carbohydrates content (Barros et al., 2011a, 2010a; Fernandes et al., 2010), which provide $31-34 \%$ of the RDA ( $130 \mathrm{~g} /$ day) for adults. Other seven pants, including the flowering aerial parts of T. mastichina $(36.6 \mathrm{~g} /$ $100 \mathrm{~g}$ ) (Barros et al., 2011a) and M. pulegium (34.4 g/100 g) (Fernandes et al., 2010) were also reported as a rich source of carbohydrates. These macronutrients are important short-term energy-storage compounds.

As shown in Table 2, information on dietary fibre content in the selected WEPs is limited. The RDA of this food component for male and female adults is 38 and $25 \mathrm{~g}$ /day, respectively (Otten et al., 2006). The basal leaves of $C$. juncea, Taraxacum obovatum (Willd.) DC., C. intybus and $B$. maritima and the midribs of basal leaves of $S$. hispanicus are those that contribute the most (15.5-20.5\%) to the daily intakes established for male adults (Table A1). For female adults, other plants arise as interesting sources of dietary fibre (with levels ranging from 3.9 to $5.6 \mathrm{~g} /$ $100 \mathrm{~g}$ ), namely the four species of wild asparagus (A. acutifolius, $H$. lupulus, T. communis and B. dioica) (García Herrera, 2014; Martins et al., 2011), the basal leaves of $P$. rhoeas, $R$. pulcher, $R$. papillaris, $S$. oleraceus and A. azurea (García-Herrera et al., 2014b; García Herrera, 2014; GuilGuerrero et al., 1998; Trichopoulou et al., 2000), the young shoots with leaves of F. vulgare (García Herrera, 2014; Trichopoulou et al., 2000), the bulb and pseudostem of A. ampeloprasum (García-Herrera et al., 2014a, 2013), and the aerial parts of $M$. fontana (García Herrera, 2014; Pereira et al., 2011; Tardío et al., 2011). Thus, the inclusion of these plants in contemporary diets can potentially increase the dietary fibre intake.

The ash content corresponds to the total amount of minerals present within a food. In addition to high levels of fat and carbohydrates, the immature fruits of $M$. sylvestris also present the higher ash content $(7.0 \mathrm{~g} / 100 \mathrm{~g})$ (Barros et al., 2010b). With high levels also arise the leaves and stems of $G$. hederacea (Barros et al., 2011a), the leaves of $F$. vulgare and M. sylvestris (Barros et al., 2010a, 2010b), the basal leaves of $B$. maritima and P. rhoeas (García Herrera, 2014), the inflorescences $F$. vulgare (Barros et al., 2010b) and the flowering aerial parts of T. pulegioides (Fernandes et al., 2010).
Based on the amount (mean value) and calorific contribution from proteins (4 kcal/100 g), carbohydrates (4 kcal/100 g), fat (9 kcal/ $100 \mathrm{~g}$ ) and dietary fibre (2 kcal/100 g) (Regulation (EU) No 1169/ 2011), it was possible to calculate the energetic value for each edible plant (Table 2). The plant parts with the highest energetic value are the flowering stems of $M$. sylvestris and the inflorescences of T. pulegioides ( 214 and $203 \mathrm{kcal} / 100 \mathrm{~g}$, respectively). Based on the reference intakes for energy (2000 kcal/day, for adults) (Regulation (EU) No 1169/ 2011), a 100-g portion of these plants only contributes in $\sim 10-11 \%$. However, it is a daily amount difficult to reach, since the flowering stems of $M$. sylvestris are usually consumed as infusions to relieve stomach pain and to regulate the intestine, while the inflorescences of $T$. pulegioides are used as a condiment or spice and in tisanes (Carvalho, 2010). The contribution of all the other plants is lower than $10 \%$. Therefore, all these WEPs are appropriate foods for low-calorie diets.

\subsection{Individual sugars}

The composition in individual sugar molecules of the selected WEPs is presented in Table 3. These compounds are included within the carbohydrates fraction and can be classified by the number of sugar units into monosaccharides (such as fructose and glucose), disaccharides (such as sucrose and trehalose) and oligosaccharides (such as raffinose). F. vulgare leaves, stems and inflorescences present a total sugar content of 6570,4920 and $4070 \mathrm{mg} / 100 \mathrm{~g}$, respectively (Barros et al., 2010b). The sugars fraction of these $F$. vulgare edible parts is composed by $70-72 \%$ fructose, $23-30 \%$ glucose and $0-5 \%$ sucrose. This plant has important culinary and medicinal uses (Table 1). Shoots, tender leaves and stems are chewed and sucked due to its exquisite aniseed flavour and used as vegetables (raw as a snack or in salads, cooked), seasonings, and food preservatives. The stems are traditionally used in the brines prepared for the olives' cure. Herbal beverages prepared with fresh tender or dried flowering stems are drunk chilled or hot, depending on the season (Carvalho, 2010; Tardío et al., 2006). In fact, the culinary value of this plant might be related to its organoleptic properties and high levels of sugars.

In general, while the highest sugars content is presented in the flowering parts of the selected wild plants, the lowest amounts are found in leafy vegetables. The flowering parts of Malva sylvestris (Barros et al., 2010a), M. pulegium (Fernandes et al., 2010), R. ulmifolius (Barros et al., 2010e), F. vulgare (Barros et al., 2010b) and P. tridentatum (Pinela et al., 2011) were reported as having a total sugars content ranging from $2066 \mathrm{mg} / 100$ (in P. tridentatum) to $5508 \mathrm{mg} / 100 \mathrm{~g}$ (in $M$. sylvestris). Some of these plant parts have been used as condiment and/or in herbal beverages to treat a number of health conditions (Table 1). In turn, amounts lower than $700 \mathrm{mg} / 100 \mathrm{~g}$ were detected in $P$. oleracea (Petropoulos et al., 2015), N. officinale, $R$. induratus (Pereira et al., 2011; Pinela et al., 2016c), R. acetosella, B. officinalis and M. fontana (Pereira et al., 2011), wild greens commonly eaten raw in salads or cooked (Table 1).

As presented in Table 3, fructose and glucose are the most abundant sugars in almost all plants. These molecules are absorbed by the human body and transported to the cells as a source of energy. High levels of these reducing sugars were reported in flowers of $M$. sylvestris (Barros et al., 2010a), flower buds of R. ulmifolius (Barros et al., 2010e) and leaves, stems and inflorescences of $F$. vulgare (Barros et al., 2010b). In turn, the flowering parts of M. pulegium (Fernandes et al., 2010), the flowering stems and leaves of $M$. sylvestris (Barros et al., 2010a) and the inflorescences and leafy flowering stems of $H$. stoechas (Barros et al., 2010e) were those with the highest sucrose content (702-1872 mg/ $100 \mathrm{~g}$ ). Nevertheless, if considering the relative percentage of each sugar, it is possible to verify that the sugars fraction of $P$. tridentatum, $T$. communis, $B$. dioica and $P$. oleracea is mainly formed by fructose ( $>47 \%$ ), while glucose predominates in F. vulgare, T. mastichina, $M$. sylvestris and $O$. vulgare ( $>50 \%$ ). Despite low in sugars, sucrose was the most abundant sugar molecule in B. officinalis (62\%) and $C$. 
Table 3

Composition in individual sugars (mg/100 g) of the selected WEPs. It is presented the mean value and, in parentheses, the range of variability of the literature data.

\begin{tabular}{|c|c|c|c|c|c|}
\hline Plant species $\left(\mathrm{Ep}^{\mathrm{a}}\right)$ & Fructose & Glucose & Sucrose & Total sugars & Reference \\
\hline A. acutifolius & $384(363-404)$ & $305(299-311)$ & $658(639-676)$ & $1423(1380-1466)$ & Martins et al. (2011) \\
\hline B. officinalis & $18(15-22)$ & $76(68-84)$ & $200(183-217)$ & $324(302-345)$ & Pereira et al. (2011) \\
\hline B. dioica & $590(576-604)$ & $508(493-523)$ & $98(93-100)$ & $1248(1216-1281)$ & Martins et al. (2011) \\
\hline C. ambrosioides & $66(64-69)$ & $126(123-129)$ & $392(359-425)$ & $833(813-852)$ & Barros et al. (2013) \\
\hline F. vulgare (Ep2) & $1510(1450-1570)$ & $4710(4560-4860)$ & $350(290-410)$ & $6570(6400-6740)$ & Barros et al. (2010b) \\
\hline F. vulgare (Ep3) & $490(440-540)$ & $760(640-880)$ & $40(39-41)$ & $1290(1090-1490)$ & Barros et al. (2010b) \\
\hline F. vulgare (Ep4) & $1490(1450-1530)$ & $3430(3230-3630)$ & nd & $4920(4690-5150)$ & Barros et al. (2010b) \\
\hline F. vulgare (Ep5) & $1100(1060-1140)$ & $2940(2830-3050)$ & $30(29-31)$ & $4070(3910-4230)$ & Barros et al. (2010b) \\
\hline G. hederacea & $150(140-160)$ & $80(60-100)$ & $400(340-460)$ & $1040(970-1110)$ & Barros et al. (2011b) \\
\hline H. stoechas & $389(374-404)$ & $225(217-233)$ & $702(668-736)$ & 1476 (1449-1503) & Barros et al. (2010e) \\
\hline M. sylvestris (Ep1) & $431(377-486)$ & $747(645-848)$ & 941 (934-948) & $2752(2631-2872)$ & Barros et al. (2010a) \\
\hline M. sylvestris (Ep2) & 2399 (2360-2437) & 2025 (1987-2061) & $680(666-693)$ & 5508 (5436-5579) & Barros et al. (2010a) \\
\hline M. sylvestris (Ep3) & $218(201-234)$ & 827 (789-865) & $60(44-76)$ & $1251(1197-1306)$ & Barros et al. (2010a) \\
\hline M. sylvestris (Ep4) & $803(762-844)$ & $1078(1037-1119)$ & $750(728-773)$ & $3336(3225-3447)$ & Barros et al. (2010a) \\
\hline M. pulegium & 969 (924-1013) & $1366(1277-1455)$ & $1872(1759-1986)$ & 4576 (4329-4823) & Fernandes et al. (2010) \\
\hline M. fontana & $36(28-44)$ & $48(47-49)$ & $21(19-23)$ & $137(121-152)$ & Pereira et al. (2011) \\
\hline N. officinale & $85(59-113)$ & $63(50-72)$ & $45(18-79)$ & $206(192-228)$ & Pereira et al. (2011), Pinela et al. (2016a) \\
\hline O. vulgare & $190(180-200)$ & $580(570-590)$ & $300(299-301)$ & $1120(1100-1140)$ & Barros et al. (2011b) \\
\hline P. oleracea & $259(118-352)$ & $86(52-138)$ & $151(75-271)$ & $549(293-785)$ & Petropoulos et al. (2015) \\
\hline P. tridentatum & $1368(1325-1411)$ & $466(447-486)$ & 227 (216-239) & $2066(2031-2101)$ & Pinela et al. (2011) \\
\hline R. ulmifolius (Ep1) & $1692(1677-1707)$ & $1885(1870-1900)$ & $432(427-437)$ & 4487 (4477-4497) & Barros et al. (2010e) \\
\hline R. ulmifolius (Ep2) & $284(248-320)$ & $382(349-414)$ & $229(204-255)$ & $1032(931-1133)$ & Barros et al. (2010e) \\
\hline R. acetosella & $65(65-66)$ & $80(79-81)$ & $23(15-31)$ & $250(229-271)$ & Pereira et al. (2011) \\
\hline$R$. induratus & $283(157-418)$ & $254(103-402)$ & $94(62-151)$ & $697(452-945)$ & Pereira et al. (2011), Pinela et al. (2016c) \\
\hline T. communis & $640(618-661)$ & $301(277-324)$ & $116(108-124)$ & $1279(1258-1301)$ & Martins et al. (2011) \\
\hline T. mastichina & $450(440-460)$ & $970(860-1080)$ & $20(19-21)$ & $1440(1330-1550)$ & Barros et al. (2011b) \\
\hline T. pulegioides & $115(115-116)$ & $173(157-188)$ & $555(544-565)$ & 1251 (1183-1319) & Fernandes et al. (2010) \\
\hline
\end{tabular}

Some values were converted from a dry weight basis or other units.

nd: not detected.

adible part (Ep) described in Table 1.

ambrosioides (47\%).

According to the Regulation (EU) No 1169/2011 of the European Parliament and of the Council, the reference intakes for sugars is $90 \mathrm{~g}$ for adults. A 100-g portion of the selected wild plants contributes to less than $7.5 \%$ for the intake of these macronutrients. Sugars make up about $38 \%$ of the carbohydrates fraction of $B$. dioica and $30-31 \%$ of the carbohydrates fraction of the $F$. vulgare shoots and T. communis. The three plants reported as a source of carbohydrates ( $M$. sylvestris immature fruits, T. pulegioides and O. vulgare) (Barros et al., 2011a, 2010a; Fernandes et al., 2010) present only $3 \%$ of individual sugars in the composition of these nutritional value indicator. This means that other constituents (such as starch and polyols or dietary fibre) are present in greater quantity in this fraction (Smolin and Grosvenor, 2013). In fact, when the dietary fibre content is not analyzed, it is included in the carbohydrates fraction that can be calculated by difference (AOAC, 2016). In this case, the result is expressed in total carbohydrates content. On the other hand, the result is expressed in available carbohydrates content when the dietary fibre is not included.

\subsection{Fatty acids}

The relative percentage of palmitic (C16:0), oleic (C18:1n-9), linoleic (C18:2n-6) and $\alpha$-linolenic (C18:3n-3) acids and of saturated fatty acids (SFA), monounsaturated fatty acids (MUFA) and polyunsaturated fatty acids (PUFA) in the selected edible wild species is presented in Table 4 . In many cases, the crude fat is composed by more than $90 \%$ of these four fatty acids. C16:0 predominates in the midribs of basal leaves of $S$. marianum (28.7\%) (Morales et al., 2012b), in the bulb and pseudostem of A. ampeloprasum (26.4\%) (García-Herrera et al., 2014a; Morales et al., 2012b) and in stems of $F$. vulgare (25.4\%) (Barros et al., $2010 \mathrm{~b}$ ). However, the higher levels of SFA ( $>51 \%$ ) were reported in $B$. officinalis (Pereira et al., 2011), mainly due to the contribution of C16:0 (12\%), C20:0 (11.9\%) and C22:0 (12\%). The relative percentage of C18:1n-9 was reported to be particularly high in leaves and stems of $G$. hederacea (35.1\%) (Barros et al., 2011a), but also in the edible parts of P. oleracea (12.4\%) (Petropoulos et al., 2015) and T. pulegioides (11.4\%) (Fernandes et al., 2010). These species also show the highest MUFA content (36.2, 15.1 and $12.8 \%$, respectively).

Regarding PUFA, levels above $80 \%$ were reported in young shoots with leaves of $O$. vulgare, in basal leaves of $C$. intybus, $P$. rhoeas, $R$. pulcher, A. azurea and $S$. oleraceus, in aerial parts of $N$. officinale, and in leaves of M. sylvestris (Barros et al., 2011a; Morales et al., 2012b; Pereira et al., 2011). These species have the highest percentage of C18:3n-3 (ranging from 60.5 to $68.4 \%$; Table 4); except for S. oleraceus where this fatty acid was not detected. In this plant, $\gamma$-linolenic acid (C18:3n-6) was quantified as the most abundant one (66.3\%) (Morales et al., 2012b), which was also present in high amounts in B. officinalis (10.9\%) (Pereira et al., 2011). C18:3n-3 is precursor of the long-chain $n$ 3 PUFA eicosapentaenoic (C20:5n-3) and docosahexaenoic (C22:6n-3) acids. However, humans have a limited capacity for the conversion of C18:3n-3 to C20:5n-3 and C22:6n-3 (Baker et al., 2016). The PUFA C18:2n-6 constitutes $40-\sim 54 \%$ of the crude fat of A. ampeloprasum, $M$. sylvestris (immature fruits), A. acutifolius, T. communis and F. vulgare (shoots) (Barros et al., 2010a, 2010b; García-Herrera et al., 2014a; Martins et al., 2011; Morales et al., 2012b). The $n-6$ PUFA C18:2n-6 and the $n-3$ PUFA C18:3n-3 are essential fatty acids that must be obtained from dietary sources (Baker et al., 2016). A daily intake of 17/12 $\mathrm{g}$ of C18:2n- 6 and 1.6/1.1 g of C18:3n-3 is recommended for male/female adults to prevent a number of diseases (Otten et al., 2006).

In general, the WEPs under review have a healthy fatty acids profile, with PUFA/SFA ratios higher than 0.45 . Its inclusion in the human diet may be beneficial, since the intake of essential fatty acids have been linked with optimal brain and vision function, reduction of cardiovascular, inflammatory and autoimmune diseases, and cancer prevention (Baker et al., 2016; Kaur et al., 2014; Simopoulos, 2002). These beneficial effects may be related to different mechanisms, including alteration in cell membrane composition, gene expression or eicosanoid production (Kaur et al., 2014). 


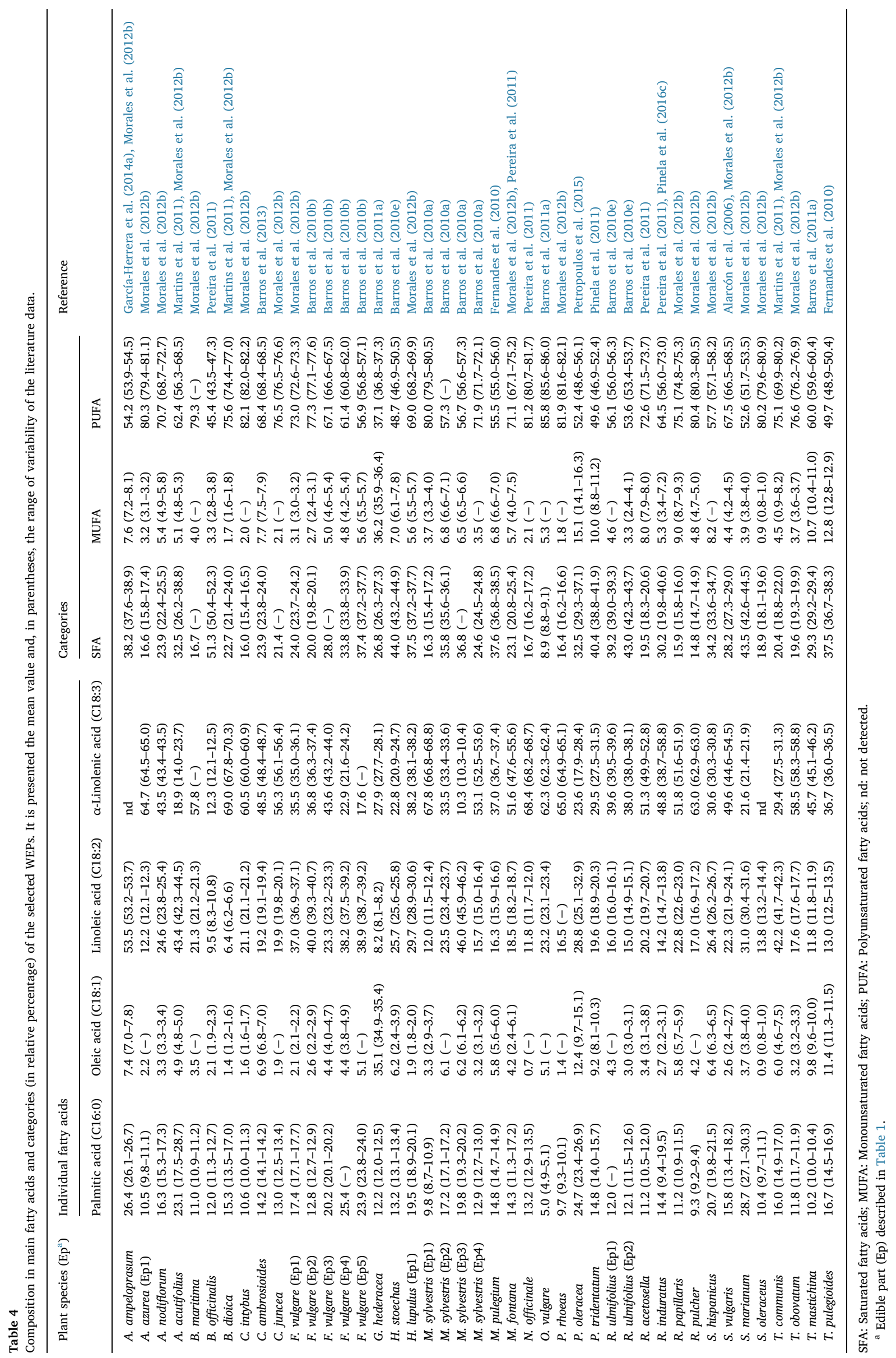




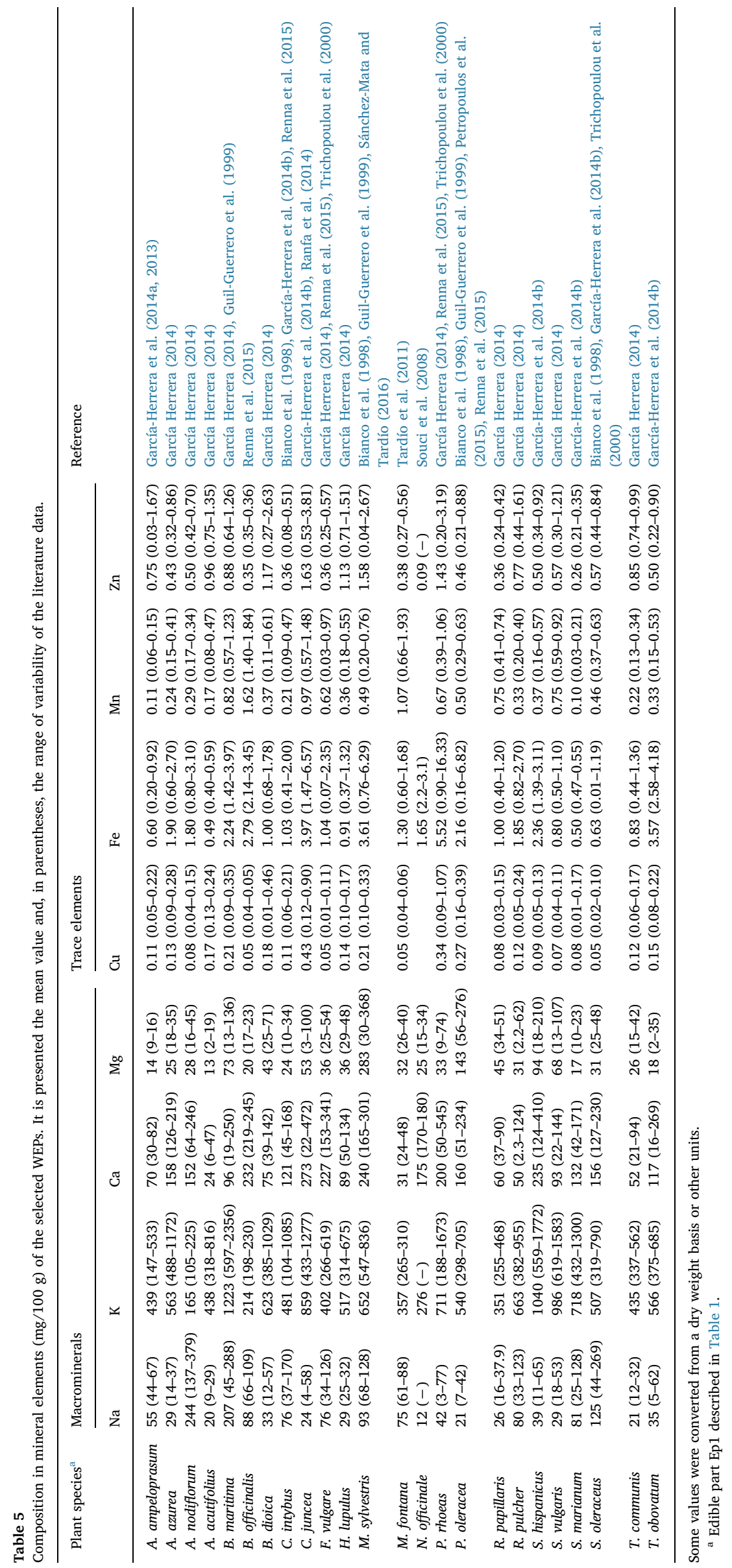




\subsection{Mineral elements}

Minerals are essential nutrients for the proper functioning of the human body (Gupta and Gupta, 2014; Otten et al., 2006; Quintaes and Diez-Garcia, 2015). They can be grouped into macrominerals (needed in higher amounts by the human body, such as sodium (Na), potassium $(\mathrm{K})$, calcium $(\mathrm{Ca})$ and magnesium $(\mathrm{Mg})$ ) and trace elements (required in lower amounts, such as copper $(\mathrm{Cu})$, iron $(\mathrm{Fe})$, manganese $(\mathrm{Mn})$ and zinc ( $\mathrm{Zn})$ ). The composition in macrominerals and trace elements of the selected WEPs is presented in Table 5. The range of $\mathrm{Na}$ in the selected edible plants is between $12 \mathrm{mg} / 100 \mathrm{~g}$ of edible portion in $N$. officinale (Souci et al., 2008) and $244 \mathrm{mg} / 100 \mathrm{~g}$ in the young stems with leaves of Apium nodiflorum (García Herrera, 2014), while that of $\mathrm{K}$ is between $165 \mathrm{mg} / 100 \mathrm{~g}$ in the last plant and $1223 \mathrm{mg} / 100 \mathrm{~g}$ in the basal leaves of B. maritima (García Herrera, 2014; Guil-Guerrero et al., 1999). In fact, only A. nodiflorum stood out as a source of Na (a 100-g portion contributes in $16.3 \%$ for the RDA; Table A1). The contribution of all other plants (except for B. maritima) is lower than $9 \%$. Besides B. maritima, the edible parts of $S$. hispanicus, $S$. vulgaris, $C$. juncea, $S$. marianum, $P$. rhoeas are also sources of $\mathrm{K}$, with levels exceeding $711 \mathrm{mg} / 100 \mathrm{~g}$ (García-Herrera et al., 2014b; García Herrera, 2014; Guil-Guerrero et al., 1999; Ranfa et al., 2014; Renna et al., 2015; Trichopoulou et al., 2000). The RDA for $\mathrm{K}$ is $4700 \mathrm{mg}$ /day for individuals with 14 or more years old (Otten et al., 2006). This nutrient is easily absorbed by the body and essential to the cells. Its deficiency, despite uncommon, can cause muscle weakness, cardiac arrhythmias, high blood pressure (hypertension) and risk of cardiovascular diseases (Stein, 2010).

$\mathrm{Ca}$ is the most abundant element in the human body. It promotes the bone health, reduces the risk of osteoporosis and helps to prevent cardiovascular diseases (Gupta and Gupta, 2014). Eleven wild plant parts were found to be interesting sources of Ca (which 100-g portion provides more than $15 \%$ of the RDA for adults; Table A1), namely the basal leaves of $C$. juncea, $B$. officinalis, $P$. rhoeas, A. azurea and $S$. oleraceus, the midribs of basal leaves of $S$. hispanicus, the leaves of $M$. sylvestris and $P$. oleracea, the aerial parts of $N$. officinale, and the young stems with leaves of $F$. vulgare and A. nodiflorum (Bianco et al., 1998; García-Herrera et al., 2014b; García Herrera, 2014; Guil-Guerrero et al., 1999; Petropoulos et al., 2015; Ranfa et al., 2014; Renna et al., 2015; Souci et al., 2008; Trichopoulou et al., 2000). These wild plants are traditionally consumed raw in salads, cooked or sautéed (Table 1).

$\mathrm{Mg}$ is the fourth most abundant cation in the body and plays an important role in many physiological processes (Swaminathan, 2003). The leaves of $M$. sylvestris and P. oleracea present the highest levels of $\mathrm{Mg}$ (283 and $143 \mathrm{mg} / 100 \mathrm{~g}$, respectively; Table 5) (Bianco et al., 1998; Guil-Guerrero et al., 1999; Petropoulos et al., 2015). A 100-g portion of these vegetables provides about $67 / 88 \%$ and $34 / 45 \%$ of the RDA of Mg established for male/female adults, respectively (Table A1). The edible parts of $S$. hispanicus, B. maritima, S. vulgaris and C. juncea also arise as sources of this macromineral, with amounts between 53 and $94 \mathrm{mg} /$ 100 g (García-Herrera et al., 2014b; García Herrera, 2014; GuilGuerrero et al., 1999; Ranfa et al., 2014).

The basal leaves of $C$. juncea and $P$. rhoeas and the leaves of $P$. oleracea present a high content of $\mathrm{Cu}$ (ranging from $0.27 \mathrm{mg} / 100 \mathrm{~g}$ in $P$. oleracea to $0.43 \mathrm{mg} / 100 \mathrm{~g}$ in C. juncea) (Table 5) (Bianco et al., 1998; García-Herrera et al., 2014b; García Herrera, 2014; Guil-Guerrero et al., 1999; Petropoulos et al., 2015; Ranfa et al., 2014; Renna et al., 2015; Trichopoulou et al., 2000). Its contribution for the RDA of $900 \mu \mathrm{g} /$ day established for $\mathrm{Cu}$ was higher than $30 \%$ (Table A1). The edible parts of M. sylvestris (leaves), B. maritima, B. dioica, A. acutifolius, T. obovatum and $H$. lupulus were also interesting dietary sources of this trace element (Bianco et al., 1998; García-Herrera et al., 2014b; García Herrera, 2014; Guil-Guerrero et al., 1999). Regarding Fe, a 100-g portion of basal leaves of P. rhoeas, C. juncea, T. obovatum and B. officinalis and of $M$. sylvestris leaves is enough to provide more than $30 \%$ of the RDA for male adults $(8 \mathrm{mg} /$ day), but only the first plant provides the same RDA for female adults (18 mg/day). As shown in Table A1, other plants can be interesting sources of Fe. A deficiency in Fe can cause anaemia (Quintaes and Diez-Garcia, 2015). Additionally, its levels can be decreased in some tissues by a deficiency in dietary $\mathrm{Cu}$, once $\mathrm{Cu}$ integrates enzymes involved in its absorption and metabolism (Gupta and Gupta, 2014; Quintaes and Diez-Garcia, 2015).

$\mathrm{Mn}$ is a trace element required for blood sugar regulation and a healthy immune system (Gupta and Gupta, 2014). Among the plants under review, the higher levels of Mn are presented by the basal leaves of B. officinalis, C. juncea, B. maritima and R. papillaris, the aerial parts of $M$. fontana, and by the tender stems with leaves of $S$. vulgaris (Table 5) (García-Herrera et al., 2014b; García Herrera, 2014; Guil-Guerrero et al., 1999; Ranfa et al., 2014; Renna et al., 2015; Tardío et al., 2011). The highest contribution for the RDA of Mn ( $\sim 70 / 90 \%$ for male/female adults) is provided by $B$. officinalis, whose content reaches 1.62 $\mathrm{mg} / 100 \mathrm{~g}$ (Renna et al., 2015). As shown in Table A1, other plants arise as interesting sources of this trace element (RDA $>15 \%$ ). The RDA of $\mathrm{Zn}$ was calculated in 11 and $8 \mathrm{mg} /$ day for male and female adults with 19 or more years old, respectively (Otten et al., 2006). This micronutrient is essential for cell division and critical in wound healing (Gupta and Gupta, 2014). The basal leaves of $C$. juncea and P. rhoeas and the leaves of M. sylvestris present the highest Zn contents (Bianco et al., 1998; García-Herrera et al., 2014b; García Herrera, 2014; GuilGuerrero et al., 1999; Ranfa et al., 2014; Renna et al., 2015; Trichopoulou et al., 2000). However, its contribution to the RDA for this trace element was higher than $15 \%$ just for female adults (Table A1). In general, the edible plants under review are not good sources of Zn.

It is interesting to note that any $100-\mathrm{g}$ portion of the different edible plants exceeds the tolerable upper intake levels (UL) for minerals. In fact, an excessive intake of certain minerals can be toxic and cause health problems (Otten et al., 2006; Stein, 2010).

\subsection{Vitamins}

Vitamins are micronutrients involved in various physiological processes and most of them must be acquired through dietary sources. In general, plants are interesting sources of hydrophilic vitamins. However, the content in lipophilic vitamins may be low, since these micronutrients are associated to the lipid fraction of the tissues and plants are fat-poor foods (Sánchez-Mata and Tardío, 2016). Table 6 presents the composition in hydrophilic (vitamin $\mathrm{B}_{9}$ and vitamin $\mathrm{C}$ ) and lipophilic (vitamins E) vitamins of the selected WEPs. There are several wild edible species whose vitamin $\mathrm{B}_{9}$ (total folates/folic acid) content remains unknown. $R$. pulcher appears at the top of the table with the highest total folates content $506.5 \mu \mathrm{g} / 100 \mathrm{~g}$ (Morales et al., 2015), a leafy vegetable whose 100 -g portion provides $\sim 127 \%$ of the RDA for adults (Table A1). Other 12 plants stand out for their high content and 4 plants as a source of this vitamin. A 100-g portion of basal leaves of $B$. maritima, A. azurea and C. intybus and of young shoots (sometimes with leaves) of $F$. vulgare, $S$. vulgaris and $A$. acutifolius provides more than $50 \%$ of the RDA of vitamin $\mathrm{B}_{9}$ (Table A1). However, the total folate content in plant foods decreases during boiling; and this should be taken into account as some of these species are cooked before consumption (Table 1). In these species (vascular plants), methyl and formyl folates are the predominant ones. The methyl folate derivatives arise in the soluble fraction (vacuoles and cytosol), while the major fraction of the formyl derivatives is found in cellular organelles (Saini et al., 2016). After ingestion, dietary folates have to be cleaved from protein carriers and polyglutamate hydrolyzed to monoglutamates in order to be absorbed in the intestine. Folates are essential for various physiological and developmental functions in the human body (Saini et al., 2016). They are critical for the embryonic development (Kim et al., 2009) and inadequate intakes may result in higher risk of certain cancers (Mason and Tang, 2016). Therefore, since humans cannot synthesize this vitamin, its intake needs to be ensured from dietary sources. In addition, the UL for folates $(1000 \mu \mathrm{g} /$ day for individuals 


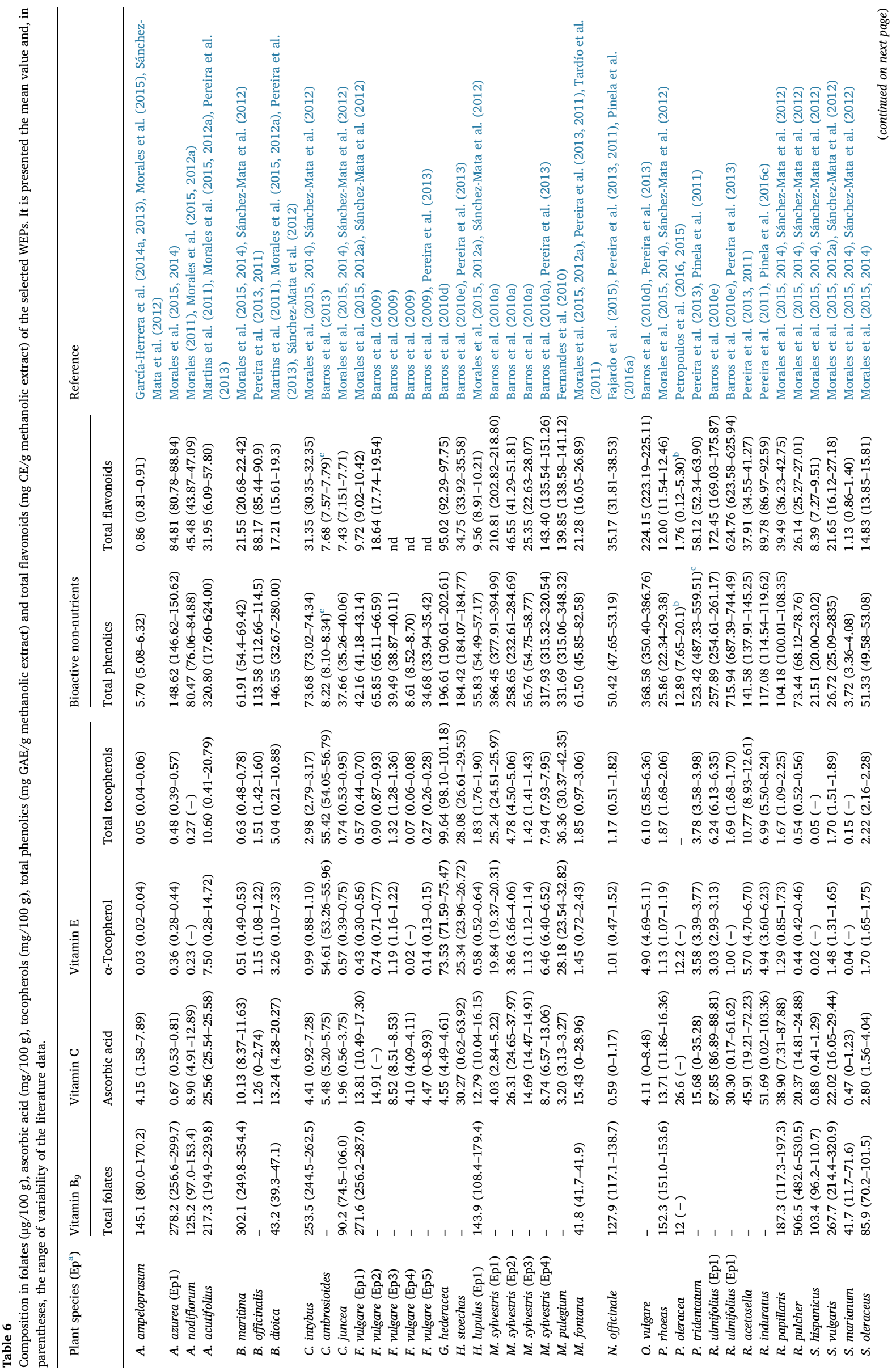


with 19 or more years old) is only applied to the synthetic forms obtained from dietary supplements and/or fortified foods (Otten et al., 2006).

Vitamin C is mainly ingested as ascorbic acid (the major form in plants) but also as dehydroascorbic acid (oxidized form). The four Polygonaceae species R. ulmifolius (Barros et al., 2010e; Pereira et al., 2013), R. induratus (Pereira et al., 2011; Pinela et al., 2016c), R. acetosella (Pereira et al., 2013, 2011) and R. papillaris (Morales et al., 2014; Sánchez-Mata et al., 2012), the wild asparagus T. communis and A. acutifolius (Martins et al., 2011; Pereira et al., 2013; Sánchez-Mata et al., 2012), P. oleracea (Petropoulos et al., 2016, 2015), H. stoechas (Barros et al., 2010e; Pereira et al., 2013) and M. sylvestris flowers (Barros et al., 2010a) were reported as having a high content of ascorbic acid (Table 6). Based on the mean values of this vitamin, it is possible to conclude that a 100-g portion of these WEPs is sufficient to provide more than $30 \%$ of the RDA of vitamin C for male and/or female individuals with 19 or more years old (Table A1). However, the ascorbic acid values described for some of the species present a high range, which may be related, in part, to the analytical method used. In fact, while some authors (Barros et al., 2013; Morales et al., 2014; Pereira et al., 2013; Pinela et al., 2016a, 2016c; Sánchez-Mata et al., 2012; Tardío et al., 2011) have analyzed the ascorbic acid by high-performance liquid chromatography (HPLC) or ultra-fast liquid chromatography (UFLC), others have used spectrophotometric assays (2,6-dichloroindophenol titrimetric method) (Barros et al., 2010a, 2010d, 2010e, 2009; Martins et al., 2011; Pereira et al., 2011; Pinela et al., 2011).

With average values between 12.79 and $22.02 \mathrm{mg} / 100 \mathrm{~g}$ of ascorbic acid, S. vulgaris, R. pulcher (Sánchez-Mata et al., 2012), P. tridentatum (Pinela et al., 2011), M. fontana (Pereira et al., 2011; Tardío et al., 2011), M. sylvestris immature fruits (Barros et al., 2010a), F. vulgare shoots (Barros et al., 2009) and young shoots with leaves (SánchezMata et al., 2012), P. rhoeas (Morales et al., 2014; Sánchez-Mata et al., 2012), B. dioica (Martins et al., 2011; Pereira et al., 2013; Sánchez-Mata et al., 2012) and H. lupulus (Sánchez-Mata et al., 2012) stand out as a source of this vitamin (a 100-g portion provides more than $15 \%$ of the RDA; Table A1). Despite the high mean vales of ascorbic acid in $R$. induratus $(51.69 \mathrm{mg} / 100 \mathrm{~g})$, R. ulmifolius (30.30 mg/100 g), H. stoechas $(30.27 \mathrm{mg} / 100 \mathrm{~g})$, P. tridentatum $(15.68 \mathrm{mg} / 100 \mathrm{~g})$ and $M$. fontana (15.43 mg/100 g) (Table 6), this vitamin was not detected or detected in small quantity by some authors (Pereira et al., 2013; Pinela et al., 2016c) in some of the samples.

Ascorbic acid has the ability to scavenge aqueous radicals and regenerate other antioxidants from their radical form (Lee et al., 2004; Niki, 2014; Niki et al., 1995). This powerful hydrophilic antioxidant can be oxidized to dehydroascorbic acid due to its involvement in the oxidative stress and then regenerated to its reduced form (Niki et al., 1995). It also facilitates the absorption of soluble non-heme Fe (Otten et al., 2006). Ascorbic acid can, however, behave as a prooxidant (Carr and Frei, 1999). It is also important to note that this vitamin is greatly affected by processing (Ottaway, 2010; Vinha et al., 2015). A study of Vinha et al. (2015) demonstrated that boiling $N$. officinale for $10 \mathrm{~min}$ promotes a significant loss of vitamin $\mathrm{C}$ and antioxidant activity. However, the phenolics content was preserved.

The amounts of $\alpha$-tocopherol and total tocopherols reported in the selected WEPs are presented in Table 6. A 100 g-portion of C. ambrosioides, $H$. stoechas, $M$. sylvestris leaves, and of the two Lamiaceae $G$. hederacea and $M$. pulegium provide more than $100 \%$ of the RDA established for vitamin E (15 mg/day for individuals with 14 or more years old (Otten et al., 2006)) (Table A1). The dietary reference intakes for vitamin $\mathrm{E}$ are calculated based on the amounts of $\alpha$-tocopherol (including the $R R R$ - $\alpha$-tocopherol that occurs naturally in foods and the $2 R$ stereoisomeric forms of $\alpha$-tocopherol that occur in fortified foods and supplements) (Otten et al., 2006). Very high levels of $\alpha$-tocopherol (71.59-75.47 mg/100 g) were reported in G. hederacea (Barros et al., 2010d), corresponding to approximately $74 \%$ of the total tocopherols 
content. Leaves of this perennial medicinal plant are recommended to the respiratory and gastrointestinal systems. Infusions prepared from the dried plant are useful for relieving colds, coughs, throat irritations and abdominal pains. Decoctions of the leaves are used for external inflammations and skin diseases (Table 1) due to its claimed anti-inflammatory and antiseptic properties (Carvalho, 2010). A high content was also reported in P. oleracea (Petropoulos et al., 2016), A. acutifolius (García-Herrera et al., 2014a, 2013), T. pulegioides (Fernandes et al., 2010), M. sylvestris leafy flowering stems (Barros et al., 2010a), $R$. acetosella (Pereira et al., 2011), $R$. induratus (Pereira et al., 2011; Pinela et al., 2016c) and O. vulgare (Barros et al., 2010d). A 100-g portion of these plants contributes in more than $30 \%$ for the RDA of vitamin E. Other plants stand out as a source of these lipophilic antioxidants. With lower levels, but still being interesting sources of this lipophilic vitamin, arise the flowering parts of $M$. sylvestris (Barros et al., 2010a), $P$. tridentatum (Pinela et al., 2011) and R. ulmifolius (Barros et al., 2010e), and the wild asparagus B. dioica and T. communis (Martins et al., 2011; Morales et al., 2012a).

Apart from $\alpha$-tocopherol, the isoforms $\beta, \gamma, \delta$ can also be detected in plant species. The isoform $\alpha$ comprises less than $30 \%$ of the total fraction of tocopherols in F. vulgare stems, S. marianum and T. mastichina. $\gamma$-Tocopherol was detected as the major vitamer in the last plant (1.70 mg/100 g) (Barros et al., 2010d) and also in C. intybus (1.88 mg/ $100 \mathrm{~g}$ ) (Morales et al., 2014). In the North-eastern region of Portugal, $T$. mastichina is used as condiment/spice for flavouring and seasoning traditional dishes and salads. It is also used to preserve olives and as a salt substituent (Table 1).

Tocopherols are amphipathic molecules in which the hydrophobic phytyl side chain is embedded within the cell membrane bilayer and the polar chromanol head is exposed to the membrane surface. This ingenious arrangement facilitates the regeneration of $\alpha$-tocopherol from the radical form ( $\alpha$-tocopheroxyl radical) by the ascorbic acid and other hydrophilic reducing agents (Lee et al., 2004). These strong antioxidants halt the lipid peroxidation chain reaction through donation of the chromanol ring phenolic hydrogen, thus maintain the integrity of the long-chain PUFA of the cell membranes (Niki, 2014). These antioxidants are involved in the non-enzymatic plant protection mechanism against the abiotic stress-induced oxidative damage, being synthesized in response to these adverse conditions (Abbasi et al., 2007; Pinela et al., 2016a). In humans, vitamin E plays a vital role in the fight against various diseases and health conditions such as oxidative stress, inflammatory and degenerative processes, cardiovascular disease and different types of cancer, mainly due to its antioxidant capacity (Galli et al., 2017; Niki, 2014). The involvement of physiological metabolites of vitamin $\mathrm{E}$ in gene regulation and homeostasis in experimental models of inflammatory, neuronal and hepatic cells, and in vivo in animal models of acute inflammation has been demonstrated (Galli et al., 2017). The UL for vitamin E (1000 mg/day for adults with 19 or more years old) is only applied to the synthetic forms obtained from dietary supplements and/or fortified foods (Otten et al., 2006).

The inclusion of WEPs in human contemporary diets can be seen as a strategy to help achieving adequate intake levels of vitamin $\mathrm{B}_{9}$, vitamin $\mathrm{C}$ and vitamin $\mathrm{E}$.

\section{Bioactive non-nutrients}

Phenolic compounds are secondary metabolites synthesized via shikimate-phenylpropanoids-flavonoids pathways. They can be grouped in different classes according to their basic skeleton, including phenolic acids $\left(\mathrm{C}_{6}-\mathrm{C}_{1}\right)$, hydroxycinnamic acids and coumarins $\left(\mathrm{C}_{6}-\mathrm{C}_{2}\right)$, naphthoquinones $\left(\mathrm{C}_{6}-\mathrm{C}_{4}\right)$, xanthones $\left(\mathrm{C}_{6}-\mathrm{C}_{1}-\mathrm{C}_{6}\right)$, stilbenes and anthraquinones $\left(\mathrm{C}_{6}-\mathrm{C}_{2}-\mathrm{C}_{6}\right)$, flavonoids and isoflavonoides $\left(\mathrm{C}_{6}-\mathrm{C}_{3}-\mathrm{C}_{6}\right)$, lignans $\left.\left(\mathrm{C}_{6}-\mathrm{C}_{3}\right)_{2}\right)$, biflavonoids $\left.\left(\mathrm{C}_{6}-\mathrm{C}_{3}-\mathrm{C}_{6}\right)_{2}\right)$, lignins $\left.\left(\mathrm{C}_{6}-\mathrm{C}_{3}\right)_{\mathrm{n}}\right)$ and condensed tannins $\left.\left(\mathrm{C}_{6}-\mathrm{C}_{3}-\mathrm{C}_{6}\right)_{\mathrm{n}}\right)$ (Vermerris and Nicholson, 2008a). In plants, these compounds are involved in growth, reproduction and defence against ultraviolet radiation or pathogens (Pandey and Rizvi, 2009). The interest of phenolic compounds comes from its health-promoting effects in humans that are conferred by antioxidant, anti-inflammatory, antitumor and antimicrobial properties, among other effects (Vermerris and Nicholson, 2008b). Therefore, these bioactive molecules affect the nutritional quality of foods (Smolin and Grosvenor, 2013) since they make the food to be functional.

The content in total phenolics and flavonoids of the selected WEPs is presented in Table 6. The fully opened flowers of $R$. ulmifolius (Fig. 1) revealed the highest levels of total phenolics (715.94 mg GAE/g extract) and flavonoids (624.76 mg CE/g extract) (Barros et al., 2010e). High levels of phenolics ( $>300 \mathrm{mg} \mathrm{GAE} / \mathrm{g}$ extract) were also measured in extracts prepared from the flowering parts of $P$. tridentatum (Pinela et al., 2011), O. vulgare (Barros et al., 2010d), M. pulegium (Fernandes et al., 2010), M. sylvestris (Barros et al., 2010a), young shots of $T$. communis and A. acutifolius (Martins et al., 2011; Morales et al., 2012a), and leaves of M. sylvestris (Barros et al., 2010a). High levels of flavonoids ( $>128 \mathrm{mg} \mathrm{GAE} / \mathrm{g}$ extract) were reported in the flowering parts of R. ulmifolius (Barros et al., 2010e), O. vulgare (Barros et al., 2010d), M. pulegium, T. pulegioides (Fernandes et al., 2010) and M. sylvestris (Barros et al., 2010a). A high content (210.81 mg GAE/g extract) was also detected in the leaves of the last plant. In turn, the lowest amounts of total phenolics ( $<13 \mathrm{mg} \mathrm{GAE} / \mathrm{g}$ extract) were detected in extracts of the midribs of basal leaves of $S$. marianum (Morales et al., 2014), bulb and pseudostem of A. ampeloprasum (García-Herrera et al., 2014a, 2013), inflorescence and upper leaves of $C$. ambrosioides (Barros et al., 2013), stems of F. vulgare (Barros et al., 2009) and leaves of P. oleracea (Petropoulos et al., 2015).

The Folin-Ciocalteu method is commonly used to measure the total phenolic content of plant matrices. This analysis is based on the formation of a blue-coloured complex between molybdenum and tungsten present in the Folin-Ciocalteu's phenol reagent upon reaction with reducing agents, which is measured spectrophotometrically at $765 \mathrm{~nm}$. As presented in Table 6, the results were expressed by the authors in mg of gallic acid equivalents (GAE) per $g$ of extract. The aluminium chloride colorimetric method is a simple way to measure the total flavonoid content. This assay is based on the formation of a flavonoid-aluminium complex that absorbs at $510 \mathrm{~nm}$. The results for total flavonoids were expressed in mg of catechin equivalents (CE) per g of extract. However, advanced chromatographic and spectrometric techniques are used to identify and quantify individual phenolic compound. The phenolic profile of C. ambrosioides was characterized by Barros et al. (2013) using an HPLC system coupled to a diode array detector (DAD). Double online detection was carried out in the DAD and in a mass spectrometer (MS) connected to the HPLC system via the DAD cell outlet. It was found that flavonoids $(768.27 \mathrm{mg} / 100 \mathrm{~g}$ of dry weight) predominate over phenolic acids $(54.07 \mathrm{mg} / 100 \mathrm{~g}$ of dry weight) in this plant. Quercetin-3-O-rutinoside, kaempferol dirhamnoside- $O$-pentoside and kaempferol 3-O-rutinoside were identified as the most abundant phenolic compounds in this plant (Barros et al., 2013).

Due to the health-promoting effects and high potential of phenolic compounds as nutraceuticals, phenolic-rich extracts have been incorporated in different food and cosmeceutical formulations. Martins et al. (2014) developed a new yogurt with a high antioxidant activity through the incorporation of free and microencapsulated extracts of $R$. ulmifolius flower buds. The phenolic extract was rich in ellagitannin derivatives, namely a sanguiin $\mathrm{H}-10$ isomer and lambertianin C. In another study, yogurt and cottage cheese were functionalized by the incorporation of an extract of $F$. vulgare aerial parts (Caleja et al., 2016a, 2016b, 2015) rich in phenolic acids and flavonoids (mostly 5-Ocaffeolyquinic acid and quercetin-3-O-glucuronide, respectively), which conferred bioactive properties to these food products. The antioxidant potential of $H$. stoechas phenolic compounds was explored for cosmetic applications (Barroso et al., 2014). The authors successfully incorporated polycaprolactone-based microspheres containing the $H$. stoechas extract rich in 3,5-O-dicaffeoylquinic acid and myricetin $O$ acetylhexoside into a moisturizer. These studies open new perspectives 
for the exploitation of wild plants as interesting sources of bioactive/ nutraceutical ingredients with applications in the food and cosmeceutical industries.

\section{Antinutritional and potentially toxic compounds}

\subsection{Oxalic acid}

In nature, oxalic acid occurs commonly as a water-soluble ( $\mathrm{Na}$ and $\mathrm{K})$ or water-insoluble $(\mathrm{Ca}, \mathrm{Mg}, \mathrm{Fe}$ and $\mathrm{Zn}$ ) salt. This compound has a quite low toxicity, but it can reduce the bioavailability of dietary Ca by the formation of an insoluble complex of calcium oxalate (Kristanc and Kreft, 2016a). Known as raphides in plants, this calcium salt is the primary constituent of the most common kind of human kidney stones (Amalraj and Pius, 2015). For this reason, the ingestion of foods with high levels of this antinutritional compound is not desirable. Some authors (Guil et al., 1996) recommend an oxalic acid/Ca ratio not higher than 2.5 to avoid this negative effect. Among the selected plants, this limit is greatly exceeded by $M$. fontana $(\sim 11.8)$ but also by other species, namely B. maritima, C. ambrosioides, S. marianum, R. pulcher, A. nodiflorum, A. acutifolius, $S$. oleraceus, $P$. oleracea, $N$. officinale and $R$. papillaris (Fig. 2 and Table A2).

Oxalic acid levels ranging from $0.7 \mathrm{mg} / 100 \mathrm{~g}$ in $R$. induratus (Pinela et al., 2016c) to $1545 \mathrm{mg} / 100 \mathrm{~g}$ in C. ambrosioides (Barros et al., 2013) have been reported (Fig. 3 and Table A2). Therefore, the consumption of $324 \mathrm{mg}$ of $C$. ambrosioides can provide the amount of oxalic acid ( $5 \mathrm{~g}$ ) set as the minimal lethal dose for an adult (a level difficult to reach through the diet). However, it should be noted that the bioavailability of ingested oxalate is estimated to be less than $15 \%$ and is influenced by a number of food composition and physiological related factors (Brogren and Savage, 2003; Kristanc and Kreft, 2016a; Liebman and AlWahsh, 2011).

Wild plants of the genus Oxalis, Rumex, Amaranthus and Chenopodium have been referred as having significant levels of oxalic acid (Guil et al., 1996; Vizgirdas and Rey-Vizgirdas, 2006). Amounts between 137 and $256 \mathrm{mg} / 100 \mathrm{~g}$ were described for R. pulcher, R. papillaris (Morales et al., 2014; Sánchez-Mata et al., 2012) and $R$. acetosella (Pereira et al., 2013); but a small amount of $0.7 \mathrm{mg} / 100 \mathrm{~g}$ was reported in tender leaves of $R$. induratus (Pinela et al., 2016c). Contrariwise, a high content in oxalic acid was found by Guerra et al. (2008) in an aqueous extract of the same plant. The authors also verified that the oxalic acid content vary depending on the development stage of the plant and environmental conditions. In another study, it was demonstrated that the harvest time and the nitrate to ammonium ratios affect the oxalic acid content in hydroponically grown $P$. oleracea plants (Palaniswamy et al., 2004). Levels ranging from 371 to $753 \mathrm{mg} /$ $100 \mathrm{~g}$ were reported by Petropoulos et al. (2015) in this plant. These observations can also be deduced from the range of values reported for oxalic acid in $S$. hispanicus, $T$. obovatum, T. communis, $S$. marianum, A. ampeloprasum, C. juncea and $R$. pulcher (Fig. 3 and Table A1), in which the variation exceeds $100 \%$.

So far, it is not clearly known whether the oxalic acid is harmful by itself or only when it is in the form of calcium oxalate (Kristanc and Kreft, 2016a). Despite this, people who easily form kidney stones should give preference to plant foods with a low oxalic acid content, like the basal leaves of $C$. intybus, T. obovatum and $C$. juncea (Morales et al., 2014; Sánchez-Mata et al., 2012), the wild asparagus T. communis, H. lupulus and B. dioica (Pereira et al., 2013; Sánchez-Mata et al., 2012), the bulb and pseudostem of $A$. ampeloprasum (García-Herrera et al., 2014a; Sánchez-Mata et al., 2012), or the flowering parts of $M$. sylvestris and P. tridentatum (Barros et al., 2013; Pereira et al., 2013), which provide less than $70 \mathrm{mg} / 100 \mathrm{~g}$ of oxalic acid (Table 7) and have an oxalic acid/Ca ration lower than 2.5 (Fig. 2).

\subsection{Pyrrolizidine and pyrrolidine alkaloids}

Pyrrolizidine alkaloids are of special concern to human health. More than 660 compounds have been identified in more than 6000 plant

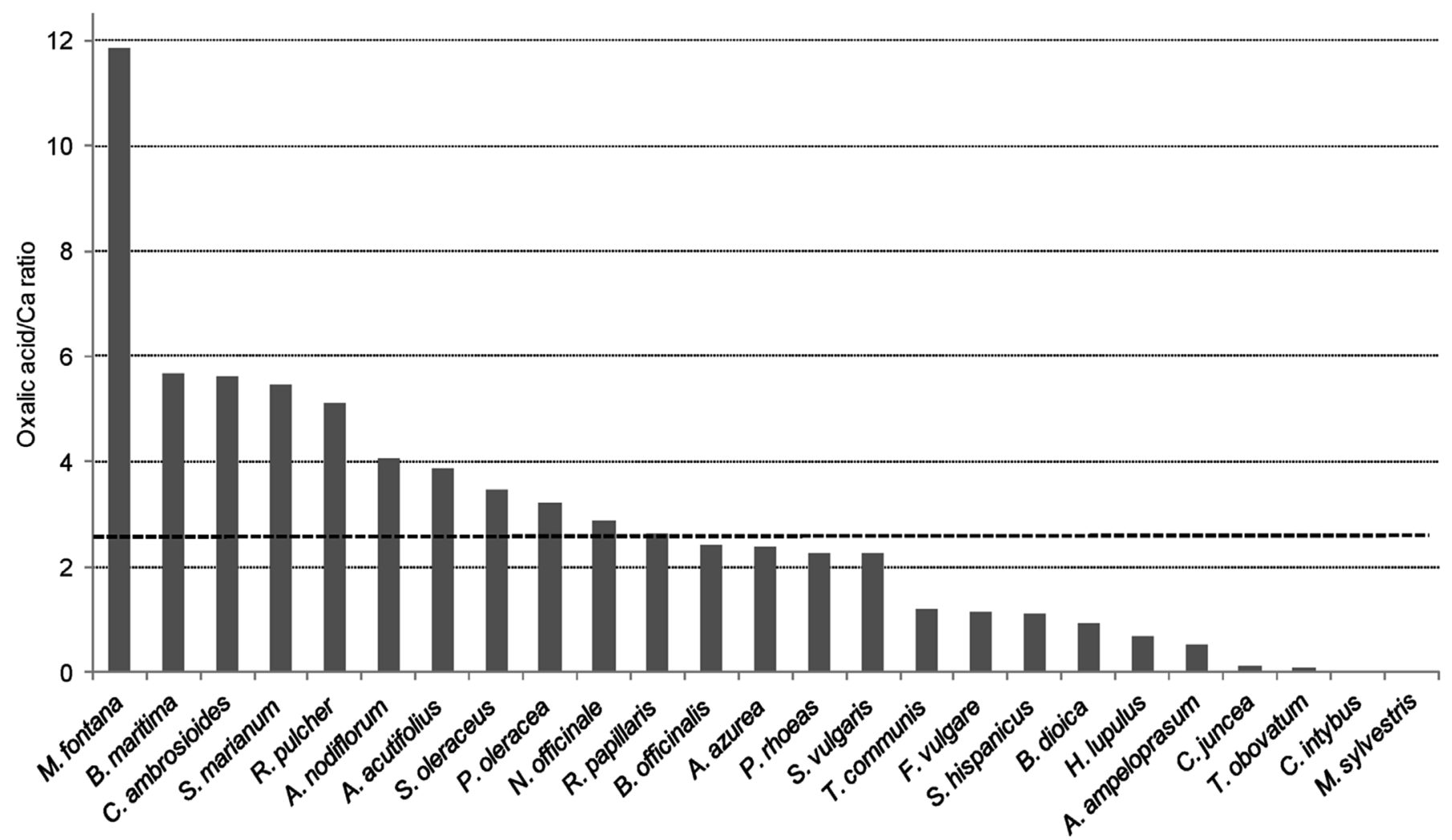

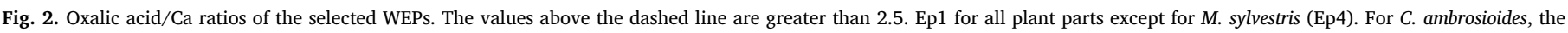
oxalic acid/Ca ratio was calculated based on the Ca levels of the USDA tables. The represented values are shown in Table A2. 


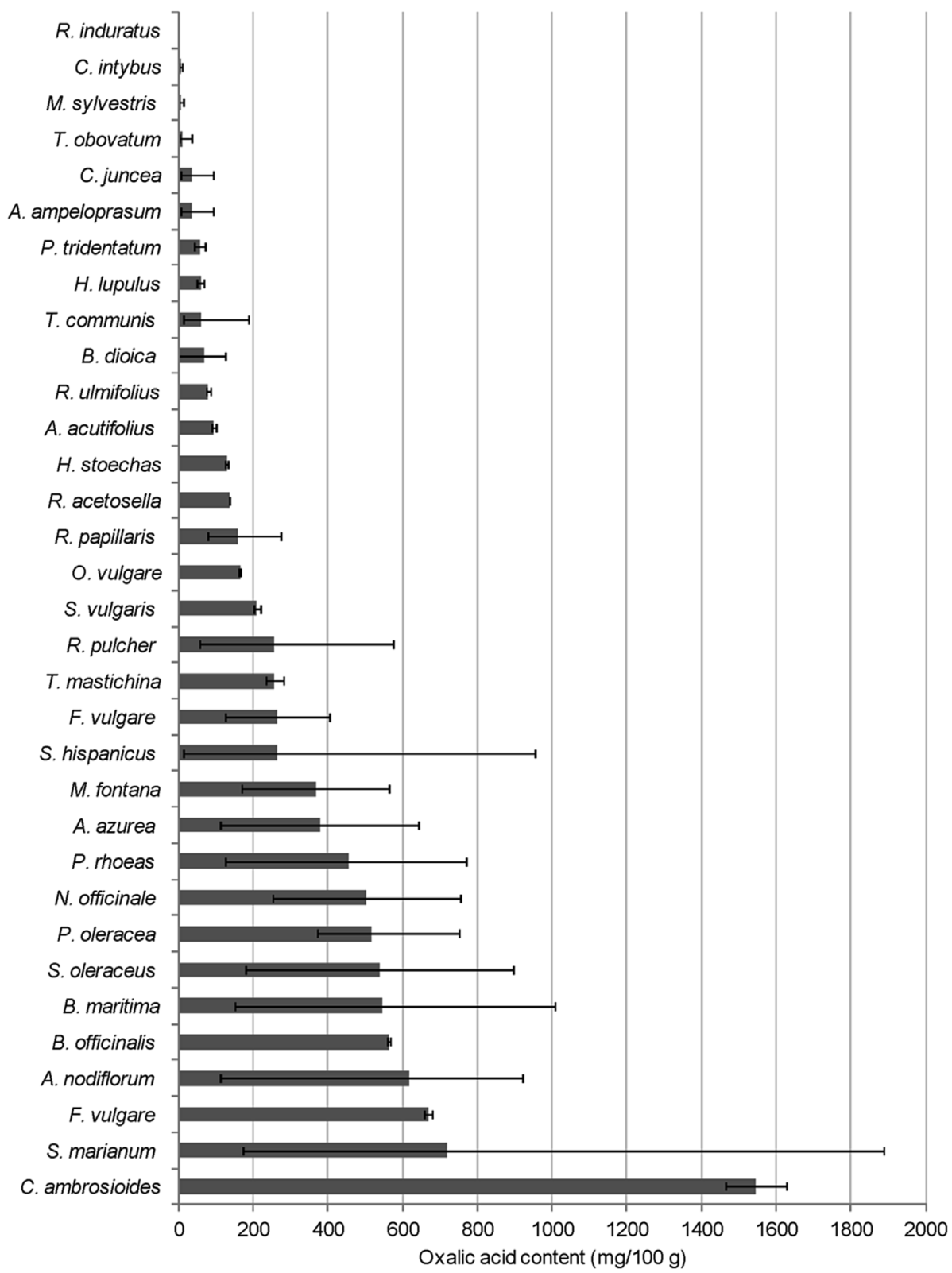

Fig. 3. Oxalic acid levels $(\mathrm{mg} / 100 \mathrm{~g})$ reported in the selected WEPs. It is presented the mean value (dark bar) and the minimum and maximum values reported in the literature. The represented values are shown in Table A2.

species worldwide, belonging mainly to the families Asteraceae, Boraginaceae, Fabaceae (tribe Crotalarieae) and Orchidaceae. Roughly half of these compounds exhibit chronic toxicity (Chen et al., 2010; Kristanc and Kreft, 2016b; Smith and Culvenor, 1981). Curiously, species containing these alkaloids are probably the most common poisonous plants affecting livestock and wildlife (Chen et al., 2010). Structurally, pyrrolizidine alkaloids are ester alkaloids composed of necine (two fused five-membered rings joined by a single nitrogen atom) and necic acid (one or two carboxylic ester arms). The toxic ones are esters of unsaturated necines having a 1,2-double bond in their base moiety. These compounds are well known for their hepatotoxic effects, but many of them are often pneumotoxic, genotoxic and carcinogenic (EFSA, 2011; Kristanc and Kreft, 2016b; Roeder, 1999). Although pyrrolizidine alkaloids themselves show a relatively low acute toxicity, they undergo a toxication process in the liver, which is the first organ to be affected. First, after absorption, a hydroxyl group is introduced in the necine at positions 3 or 8 by cytochrome P450 enzymes in the liver, originating unstable compounds that undergo a rapid dehydration process, resulting in a second double-bond in the necine followed by spontaneous rearrangement to an aromatic pyrrole system (Wiedenfeld, 2011). Acute poisoning by pyrrolizidine alkaloids causes haemorrhagic necrosis, hepatomegaly and ascites. The subacute toxicity is characterised by occlusion of the hepatic veins and subsequent necrosis, fibrosis and liver cirrhosis. Hence, death is caused by liver failure. As shown in Table 7, pyrrolizidine alkaloids can be found in A. azurea (namely lycopsamine, laburnine (Fig. 4) and acetyllaburnine) (EFSA, 2009; Roeder, 1999) and B. officinalis seed oil (namely the hepatotoxic amabiline) (Dodson and Stermitz, 1986; EFSA, 2009; EMA, 2014; Vacillotto et al., 2013; Wretensjö and Karlberg, 2003). Both species are listed in the "compendium of botanicals reported to contain naturally occurring substances of possible concern for human health when used in food and food supplements" of the European Food Safety Authority (EFSA, 2009).

Pyrrolidine alkaloids linked with a tropane-like skeleton (namely hederacines A and B, showed in Fig. 4) were already isolated from $G$. hederacea aerial parts and revealed prominent toxicity in the brine shrimp lethality bioassay (Kumarasamy et al., 2003). 
Table 7

Potentially toxic compounds that can be found in WEPs.

\begin{tabular}{|c|c|c|c|}
\hline Plant species & $\begin{array}{l}\text { Part of possible } \\
\text { concern }\end{array}$ & Potentially toxic compound & References \\
\hline \multirow[t]{2}{*}{ A. azurea } & Unspecified parts & Pyrrolizidine alkaloids: lycopsamine, laburnine and acetyllaburnine & EFSA (2009), Roeder (1999) \\
\hline & Seeds (oil) & - & EFSA (2009), Roeder (1999), Vacillotto et al. (2013) \\
\hline B. officinalis & Seeds (oil) & Pyrrolizidine alkaloid: amabiline & EFSA (2009), EMA (2014), Vacillotto et al. (2013) \\
\hline \multirow[t]{2}{*}{ B. dioica } & Root & $\begin{array}{l}\text { Cucurbitacins B, D, E, I, J, K, L and S; cucurbitacin glycosides: } \\
\text { bryodulcoside, bryoside and bryonoside; cucurbitacin saponins: brydioside } \\
\text { A, B and C; dihydrocucurbitacins B and E; tetrahydrocucurbitacin I }\end{array}$ & $\begin{array}{l}\text { Chen et al. (2005), EFSA (2009), Gry et al. (2006), } \\
\text { Hylands and Mansour (1982), Hylands and Salama } \\
\text { (1976), Oobayashi et al. (1992), Pohlmann (1975) }\end{array}$ \\
\hline & Fruit & Brydiofin & Muñoz et al. (1992), Tardío et al. (2016) \\
\hline C. ambrosioides & $\begin{array}{l}\text { Aerial part (essential } \\
\text { oil) }\end{array}$ & Peroxygenated monoterpene: ascaridole; phenylpropanoid: safrole & $\begin{array}{l}\text { EFSA (2012, 2009), Kiuchi et al. (2002), Tucker and } \\
\text { Maciarello (1998) }\end{array}$ \\
\hline \multirow[t]{3}{*}{ F. vulgare } & $\begin{array}{l}\text { Aerial part (essential } \\
\text { oil) }\end{array}$ & Phenylpropanoids: trans-anethole and estragole (2.3-4.9\%) & EFSA $(2012,2009)$ \\
\hline & Fruit (essential oil) & Phenylpropanoid: estragole $(0.8->80 \%)$ & EFSA $(2012,2009)$ \\
\hline & Seeds (essential oil) & $\begin{array}{l}\text { Phenylpropanoid: estragole (from } 11.9 \text { to } 56.1 \% \text { in unripe seeds to } 61.8 \% \\
\text { in ripe seed) }\end{array}$ & EFSA (2012), García-Jiménez et al. (2000) \\
\hline \multirow[t]{2}{*}{ G. hederacea } & Aerial part & Pyrrolidine alkaloids: hederacines A and B & EFSA (2012), Kumarasamy et al. (2003) \\
\hline & $\begin{array}{l}\text { Flowering aerial part } \\
\text { (essential oil) }\end{array}$ & Monoterpene etheroxide: 1,8-cineole (eucalyptol, 1.9-4.6\%) & EFSA (2012) \\
\hline H. lupulus & Inflorescence & $\begin{array}{l}\text { Prenylflavonoids: 8-prenylnaringenin (hopein), xanthohumol, } \\
\text { isoxanthohumol }\end{array}$ & EFSA (2009) \\
\hline M. pulegium & $\begin{array}{l}\text { Aerial part (essential } \\
\text { oil) }\end{array}$ & $\begin{array}{l}\text { Monocyclic monoterpene ketone: pulegone ( } 71.3-90 \%) \text {; bicyclic } \\
\text { monoterpenes: menthofuran and thujones; monoterpene etheroxide: 1,8- } \\
\text { cineole (eucalyptol) }\end{array}$ & $\begin{array}{l}\text { EFSA (2012, 2009), Kristanc and Kreft (2016a), Teixeira } \\
\text { et al. (2012) }\end{array}$ \\
\hline O. vulgare & $\begin{array}{l}\text { Aerial part (essential } \\
\text { oil) }\end{array}$ & $\begin{array}{l}\text { Bicyclic monoterpene: beta-thujone (0-0.6\%); monoterpene etheroxide: } \\
\text { 1,8-cineole (eucalyptol, } 0-6.5 \%)\end{array}$ & EFSA (2012) \\
\hline P. rhoeas & Whole plant & - & $\begin{array}{l}\text { Al-Qura'n (2005), EFSA (2012), Kemal et al. (2015), } \\
\text { Tardío et al. (2016) }\end{array}$ \\
\hline Rumex sp.pl. & Whole plant & $\begin{array}{l}\text { Oxalates and hydroxyanthracene derivatives: chrysophanol, physcion, } \\
\text { emodin, aloe-emodin, rhein, barbaloin (aloin A and B) and sennosides A } \\
\text { and B }\end{array}$ & EFSA (2012) \\
\hline S. vulgaris & Root & Triterpenoid saponins: silenosides A, B and C & Glensk et al. (1998) \\
\hline S. marianum & $\begin{array}{l}\text { Flowering top and } \\
\text { seed }\end{array}$ & - & EFSA (2012) \\
\hline \multirow[t]{2}{*}{ T. communis } & Rhizome & Steroidal saponins: dioscin and gracillin; phenanthrene derivatives & $\begin{array}{l}\text { EFSA (2009), Kovács et al. (2007), Réthy et al. (2006), } \\
\text { Tardío (2005) }\end{array}$ \\
\hline & Fruit & - & Tardío et al. (2016) \\
\hline Thymus sp.pl. & $\begin{array}{l}\text { Aerial part (essential } \\
\text { oil) }\end{array}$ & Monoterpene etheroxide: 1,8-cineole (eucalyptol) & EFSA (2012) \\
\hline
\end{tabular}

\subsection{Brydiofin and cucurbitacins}

In Portugal and Spain, the crushed fruits of $B$. dioica are applied topically to mitigate rheumatic symptoms (Aceituno-Mata, 2010; Carvalho, 2010). However, Muñoz et al. (1992) identified a toxic protein called brydiofin in that fruits (Table 7) and verified that their extract have a highly toxic effect after intraperitoneal injection of $0.4 \mathrm{mg}$ per Balb/c mouse that was killed in 18 min (Muñoz et al., 1992). This lethal effect was not presented by the root and leaf extracts. However, different cucurbitacins can be found in the root of this plant (Table 7), part that is not consumed as food. Cucurbitacins are highly toxic and bitter compounds that can be isolated from about 100 species of $\mathrm{Cu}$ curbitaceae, being also found in plants belonging to the families Scrophulariaceae, Begoniaceae, Primulaceae, Liliaceae, Tropaeolaceae and Rosaceae (Gry et al., 2006; Kaushik et al., 2015). Due to the selection of non-bitter plants for food use made by our ancestors and later by plant breeders, the cucurbits currently consumed generally do not synthesize these compounds. Structurally, cucurbitacins are tetracyclic triterpenes with a cucurbitane skeleton and differ from most other tetracyclic triterpenes because they are highly unsaturated and contain many keto, hydroxy and acetoxy groups (Chen et al., 2005; Gry et al., 2006). A chronic exposure to these compounds is not expected in humans given their extremely bitter and disagreeable taste and the accidental occurrence in plant foods (Gry et al., 2006). For cucurbitacins D (Fig. 4) and I, the oral $\mathrm{LD}_{50}$ in mice is $\sim 5 \mathrm{mg} / \mathrm{kg}$ body weight; for cucurbitacin $\mathrm{E}$ and cucurbitacin E glycoside, which are the most common cucurbitacins identified in food plants, the oral $\mathrm{LD}_{50}$ values in mice are 340 and $40 \mathrm{mg} / \mathrm{kg}$ body weight, respectively (Gry et al., 2006). Animal studies have shown that exposure to cucurbitacin D promotes increased capillary permeability, irritation of the intestinal mucosa, and increased intestinal mobility. The animal's death is caused by congestion of the intestine, pancreas, liver and kidneys. In humans, mucosal irritation occurs within minutes of ingestion of cucurbitacin-containing preparations (Gry et al., 2006).

Although highly toxic, cucurbitacins began to attract much interest in the 1960s for their immense pharmacological potential (Chen et al., 2012). Using a long array of in vitro and in vivo cancer cell models, it has been shown that certain natural cucurbitacins and their derivatives have anti-proliferative and pro-apoptotic effects (with no toxicity to non-tumour tissues), being therefore recognized as promising antitumor compounds for several types of cancer (Kaushik et al., 2015; Marostica et al., 2017; Sinha et al., 2016).

\subsection{Saponins}

Saponins are a diverse group of secondary metabolites characterized by a structure containing a triterpene or steroid aglycone called sapogenin and one or more sugar chains (Güçlü-Üstündağ and Mazza, 2007; Podolak et al., 2010), which have already been identified in more than 100 plant families. The consumption of saponin-containing plant foods may be associated with beneficial and adverse effects. Saponins can act as antinutrients and, in some cases, reduce the consumption of some foods because of their bitter taste (Muzquiz et al., 2012). All legumes have triterpene-type saponins (Muzquiz et al., 2012). In fact, while triterpenoid saponins are mainly found in Magnoliopsida (former dicotyledons), steroidal saponins are more abundant in Liliopsida (former 

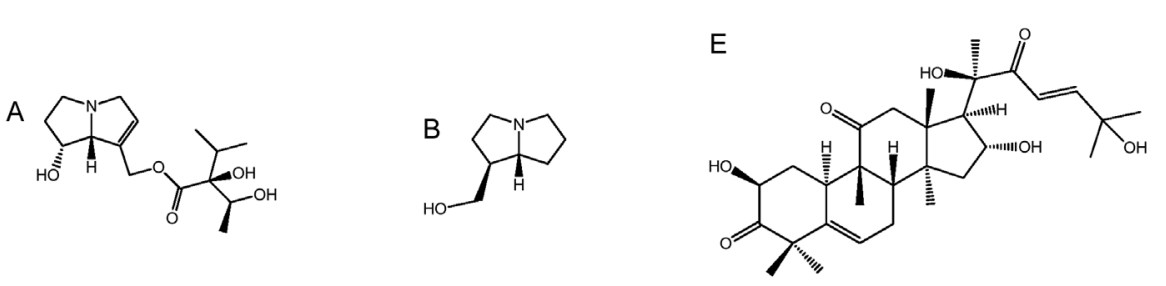

Fig. 4. Chemical structure of potentially toxic compounds that can be found in some WEPs presented in Table 7. A: lycopsamine; B: laburnine; C: hederacine A; D: hederacine B; E: cucurbitacin D; F: dioscin; G: gracillin; H: ascaridole; I: safrole; J: 8-prenylnaringenin; $\mathbf{K}$ : xanthohumol; and $\mathbf{L}$ : isoxanthohumol.

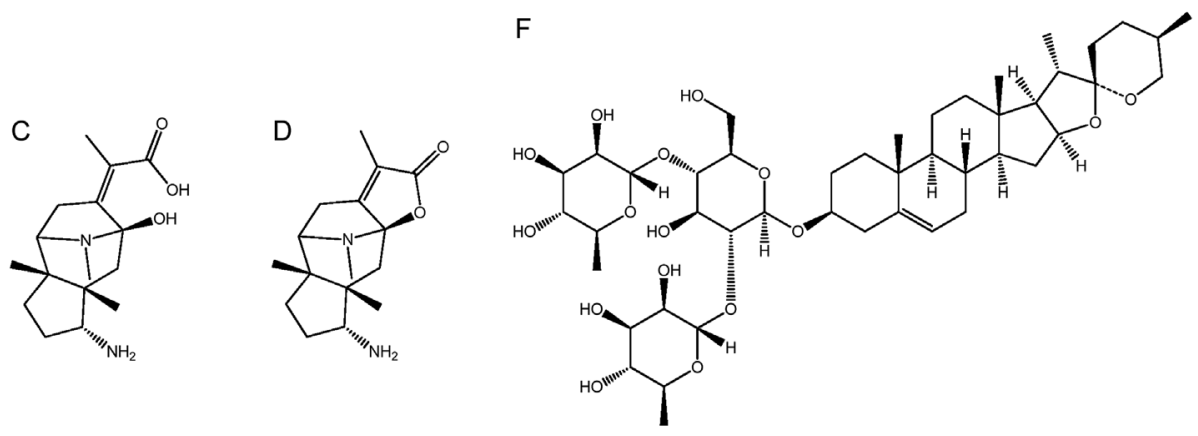

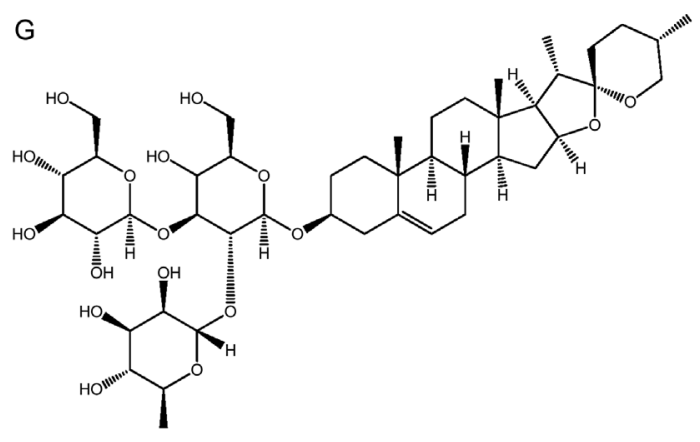<smiles>Cc1ccc(C(C)C)cc1</smiles><smiles>C=CCc1ccc2c(c1)OCO2</smiles><smiles>CC(C)CCc1c(O)cc(O)c2c1OC(c1ccc(I)cc1)CC2=O</smiles><smiles>[Y]c1cc(O)c(/C=C/c2ccc(O)cc2)c(/C=C/C(=O)O)c1CC=C(C)C</smiles><smiles>CC(C)=CCc1c(O)cc(O)c2c1OC(c1ccc(O)cc1)CC2=O</smiles>

monocotyledons) (Güçlï-Üstündağ and Mazza, 2007; Podolak et al., 2010). The structural complexity of these compounds results in a wide range of biological properties (Güçlü-Üstündağ and Mazza, 2007) among which in vitro haemolytic activity has been one of the most investigated ones. This activity is mainly attributed to their ability to interact with membrane cholesterol that leads to membrane destabilization (Podolak et al., 2010). According to Oda et al. (2000), the haemolytic effect of saponins can be related to the presence of an acyl residue or oxide-ring moiety. However, both aglycone and sugar chain play an important role for cytotoxic activity (Podolak et al., 2010).

As presented in Table 7, the steroidal saponins dioscin and gracillin (Fig. 4) were identified in rhizomes of T. communis (EFSA, 2009) and the triterpenoid saponins silenosides A, B and C were extracted from roots of S. vulgaris (Glensk et al., 1998). The pharmacokinetics of dioscin was studied by Li et al. (2005). The authors found that its bioavailability after oral administration to rats was very low $(0.2 \%)$ and sustained prolonged absorption in the intestines, where it remained at high concentrations even after $120 \mathrm{~h}$ after administration. Other studies indicated that dioscin has anti-inflammatory properties (Wu et al., 2015) and inhibits proliferation and induces apoptosis in cancer cells (Zhang et al., 2016; Zhao et al., 2016), highlighting this compound as a promising anti-inflammatory and anti-cancer drug.

\subsection{Phenanthrenes and hydroxyanthracenes}

Phenanthrenes have been reported in higher plants, mainly in the family Orchidaceae, but also in Dioscoreaceae, Combretaceae and Betulaceae families and Hepaticae class (Kovács et al., 2008). Phenanthrene derivatives with a pronounced cytotoxic activity on cervix adenocarcinoma (HeLa) cells were isolated from rhizomes of T. communis (Kovács et al., 2007; Réthy et al., 2006). Despite all the potential of this group of natural bioactive compounds as cytotoxic, anti-inflammatory, antimicrobial, spasmolytic, and antiplatelet aggregation agents (Kovács et al., 2008), their pharmacological potential is not yet sufficiently studied.

In addition to oxalates, some Rumex species may also contain hydroxyanthracene derivatives (EFSA, 2012). Eight anthracene derivatives were described in six Rumex species (Table 7), including $R$. acetosa, $R$. acetosella, $R$. crispus and $R$. obtusifolius, and the highest levels were detected in the roots (Smolarz et al., 2011).

\subsection{Monoterpenes, phenylpropanoids and prenylflavonoids}

As shown in Table 7, potentially toxic monoterpenes and phenylpropanoids can be found in the essential oil of some of the wild plants under review. All plants containing these constituents appear on the 
EFSA compendium of botanicals that have been reported to contain toxic or other substances of concern (EFSA, 2012, 2009). The bicyclic monoterpene ascaridole and the phenylpropanoid safrole (Fig. 4) can be found in C. ambrosioides essential oil (Kiuchi et al., 2002; Tucker and Maciarello, 1998). This is an essential oil with anthelmintic activity that has been used to treat parasitosis and leishmaniasis (Monzote et al., 2009). Its toxicity is mainly attributed to the presence of caryophyllene oxide, while the toxicity of ascaridole is potentiated by the availability of redox-active iron (Gille et al., 2010; Monzote et al., 2009). 1,8-Cineole (eucalyptol) is an essential oil constituent of $G$. hederacea, $M$. pulegium and O. vulgare (EFSA, 2012, 2009; Kristanc and Kreft, 2016a). It is used as food flavouring and as excipient in the pharmaceutical industry. However, this organic compound presents possibly maternal and foetal toxicity (Caldas et al., 2016).

Pulegone can be found in Mentha sp.pl., especially in M. pulegium essential oil, which also contains the bicyclic monoterpenes menthofuran and thujones (Anderson et al., 1996; Da Rocha et al., 2012; EFSA, 2012, 2009; EMA, 2016; Kristanc and Kreft, 2016a). Menthofuran is a hepatotoxin produced biosynthetically from pulegone (a compound with strong insecticidal activity) (Abdelli et al., 2016). Menthofuran is metabolically activated to an electrophilic gamma-ketoenal that is capable of covalent binding to cellular proteins to form covalent adducts (Thomassen et al., 1992). In turn, thujones are known for their neurotoxic effects (Radulović et al., 2017).

Regarding phenylpropanoids, estragole and trans-anethole have been reported as constituents of the $F$. vulgare essential oil (EFSA, 2012, 2009; García-Jiménez et al., 2000). The genotoxic and carcinogenic (mainly hepatocarcinogenic) effects of estragole are well established in several rodent models. Although trans-anethole is not genotoxic, it induces hepatocellular carcinomas in rats (Kristanc and Kreft, 2016b).

The prenylflavonoids 8-prenylnaringenin (hopein), xanthohumol and isoxanthohumol (Fig. 4) were identified as the major phytoestrogenic constituents in H. lupulus inflorescences (EFSA, 2009; Kristanc and Kreft, 2016b), compounds which impart an endocrine-disrupting potential to this plant (Kristanc and Kreft, 2016b). Costa et al. (2017) demonstrated that the ingestion of 8-prenylnaringenin and xanthohumol could ameliorate diabetic-related metabolic dysfunctions in mice by regulating glucose and lipid pathways. Isoxanthohumol exhibits antiproliferative activity against different human cancer cell lines, including those of the breast, ovarian, prostate, and colon. It also inhibits the production of prostate-specific antigen (Żołnierczyk et al., 2015).

\section{Safety precautions}

Most poisonous wild plants are recognized as dangerous by local populations due to the empirical knowledge acquired over centuries and registered in ethnobotanical studies (Aceituno-Mata, 2010; Carvalho, 2010). In addition, the consumption of botanicals of potential concern for human health is cautioned by EFSA (EFSA, 2012, 2009). Seed oils of $A$. azurea and B. officinalis, essential oils of $C$. ambrosioides, F. vulgare, $M$. pulegium, $O$. vulgare and Thymus sp.pl., roots and rhizomes of $S$. vulgaris, B. dioica and T. communis, fruits of $B$. dioica and T. communis, and some Rumex sp.pl., among others presented in Table 7 and Fig. 2, are plants of possible concern. Some of these botanicals are very bitter and, in some cases, the traditionally consumed part is not where the potentially toxic compounds accumulate. For example, cucurbitacins and steroidal saponins can be found in the roots of $B$. dioica and $T$. communis, respectively (Table 7), but the young shoots with immature leaves are the traditionally consumed parts of these wild asparagus (Table 1) (Tardío et al., 2006). Traditional knowledge warns against the toxicity of these species and considers the young shoots as the least toxic part (Carvalho, 2010). According to some informants, these wild foods should not be eaten in the flowering or fruiting stage because they can cause diarrhoea or other adverse effects (Tardio et al., 2002). In fact, ethnobotanical information describes that young shoots should be gathered only in spring before the development of immature floral buds
(Carvalho, 2010). Therefore, just cooked young shoots should be consumed (Tardío et al., 2016).

In the case of plants traditionally prepared as medicinal infusions/ decoctions (Table 1), empirical knowledge and healers indicate that the long-term use of these preparations in humans should be avoided to prevent possible adverse effects, which may differ according to the dose and physical condition of the consumer (Carvalho, 2010).

\section{Valorisation strategies, challenges and trends}

WEPs have provided a key source of nutrients to humans since prehistoric times; but their relevance to the human diet decreased first with the agricultural expansion and then with the industrial revolution (Łuczaj, 2010; Reyes-García et al., 2015). In addition, wild foods are often undervalued because of former associated perception of poverty and scarcity and their relatively low presence in contemporary urban diets. However, several studies have shown that WEPs: i) continue to contribute to food sovereignty in many regions of the world, especially in non-industrialized countries; ii) are key components of extensive farming systems and of subsistence economy; iii) hold potential to reactivate rural economies; and iv) help maintain local identities, with likely effects on biodiversity conservation (Menendez-Baceta et al., 2017). Indeed, the current limited use of wild plants is a lost opportunity for local economy and population well-being of different regions of the world (Bacchetta et al., 2016).

Interestingly, some wild species are now re-emerging in gardens and kitchens of urban areas around Europe, being increasingly found in farmers' markets, gourmet food shops, and restaurants (Euczaj et al., 2012; Tardío, 2005; Vasquezde, 2016). Nevertheless, WEPs lack recognition as significant contributors to the human diet in developed countries. Therefore, agro-ecological, nutritional, bioactivity and safety studies are of high importance for their revival and commercialization (Bacchetta et al., 2016). The revalorisation strategies herein proposed are based on the following criteria:

- Nutritional and chemical characterization: The evaluation of the nutritional value (macro- and micronutrients) and chemical composition (secondary metabolites) will highlight the most promising wild species to be included in contemporary diets or to be use as an alternative source of natural ingredients (Barros et al., 2010b). The presence of anti-nutritional and toxic compounds should be investigated to ensure the safety of WEPs and based products.

- Evaluation of bioactivities and health promoting effects: Several WEPs are considered functional foods (Pinela et al., 2016e), i.e., foods that exert beneficial physiological effects that go beyond the basic nutrition capacity. Thus, in parallel with the chemical prospecting studies (which highlight the most promising species in terms of bioactive molecules), the in vitro and in vivo evaluation of antioxidant, anti-inflammatory, antitumor, antimicrobial, antidiabetic, and cardioprotective potential of wild plant-based extracts or isolated compounds should be performed (e.g., the studies of Pereira et al. (2016), Guimarães et al. (2016) and Nikolić et al. (2014) with Tuberaria lignosa (Sweet) Samp., Chamaemelum nobile (L.) All. and Thymus sp.pl., respectively). The impact of a regular consumption of wild plant foods in the prevention of diet-related and chronic diseases should be accessed. The absence of toxicity must be always ensured to safeguard human health and well-being.

Application of innovative methods and technologies: Application of nonconventional and emerging treatments (innovative packaging systems, light treatments, irradiation, high pressures, pulsed electric fields, among others) for quality preservation and shelf-life extension of wild plant foods (Pinela et al., 2016a, 2016b, 2016c, 2016d), in order to promote their commercialization and the consumer's acceptance for minimally processed and new food products. Establishment of optimized protocols for recovery of high added-value compounds (polyphenols, terpenoids, polysaccharides, and others) 
from wild species and their by-products and production of enriched extracts to be used in industrial sectors (Pinela et al., 2017a, 2017b). - Development of new products, recipes and characteristic dishes: Development of wild plant-based foods and beverages, such as $C$. intybus-based coffee (Street et al., 2013), as well as functional ingredients to be used as nutraceuticals, preservatives, colorants, sweeteners, or antifungals in new food, pharmaceutical, or cosmeceutical formulations (Barreira et al., 2013; Barroso et al., 2014; Caleja et al., 2016a, 2016b, 2015; Martins et al., 2014). Some of these natural ingredients (antioxidants, antifungals, colorants and sweeteners) may replace specific artificial food additives used in the industry (Carocho et al., 2015; Martins et al., 2016). New recipes and characteristic dishes based on traditional uses and modes of consumption of wild edibles might raise some interest in these foods as wild products are becoming fashionable. In the Iberian peninsula and Italy, dishes incorporating T. communis, A. acutifolius, A. ampeloprasum, $N$. officinale, M. fontana, B. officinalis, M. sylvestris, $P$. rhoeas, S. hispanicus, Rumex crispus L., and Urtica dioica L. (Fig. 1) can be found in some luxury restaurants (Bicho, 2015; Łuczaj et al., 2012).

- Implementation of alternatives to wild-harvesting practices: Wild harvesting may represent a source of income for rural communities. However, an uncontrolled and irrational overexploitation promoted by economic interests may become a risk and lead to species extinction and erosion of some components within different ecosystems. Although the challenges are great, domestication and cultivation of wild species is the most sustainable alternative that offers several advantages over wild harvesting. Additionally, cultivation provides reliable botanical identification, guarantees a steady source of raw material, allows controlled post-harvest handling and, therefore, the quality control can be assured. Moreover, cultivated plant materials can be easily certified as organic or biodynamic (Schippmann et al., 2002). However, further agronomic and biotechnological research is needed.

- Agricultural and in vitro production: The most promising wild plants (native or introduced and naturalized) should be selected for cultivation in order to diversify the on-farm production. Since most of them are autochthonous plants adapted to local environments, they support the seasonal variations and adverse climatic conditions of the region, which ensure more stable productions (Molina et al., 2016). For example, S. hispanicum is already cultivated and commercialized in some regions of Spain and its shoots are sold as gourmet food product (Łuczaj et al., 2012). The agricultural interest for non-food crops for obtaining high-added value products is also attractive, namely $n-3$ fatty acids from seeds of B. officinalis (GuilGuerrero et al., 2013), tocopherols from G. hederacea (Barros et al., 2010d) and C. ambrosioides (Barros et al., 2013), phenolic compounds from R. ulmifolius (Barros et al., 2010e), inulin from C. intybus (Amaducci and Pritoni, 1998), cucurbitacins from B. dioica roots (Chen et al., 2005; Gry et al., 2006; Hylands and Mansour, 1982; Hylands and Salama, 1976; Oobayashi et al., 1992; Pohlmann, 1975), and prenylflavonoids from $H$. lupulus inflorescences (Kristanc and Kreft, 2016b).

- Breeding and genetic characterization of crop wild relatives: The genetic improvement of crop wild relatives is a scientific challenge that should be pursued. Advanced biotechnological and molecular tools could facilitate the discovery of new genes and open new opportunities for plant breeding (Amirul et al., 2014). In fact, wild relatives maintain a much higher level of genetic diversity than domesticated cultivars (Zhang et al., 2017). Using omics-scale technologies and advanced techniques, genes of interest can be transferred from wild species to cultivated crops. The development of novel crop varieties can help overcame critical challenges of food production related to the deleterious effects of climate change and human activities as well as diverse environmental stresses (Zhang et al., 2017).

- In situ and ex situ conservation: Plant genetic resources strategies and techniques play an important role in wild species conservation and management. Particularly on-farm conservation and protected areas defined (in situ conservation measures), as well as ex situ conservation measures supporting in situ conservation, have great relevance to wild edibles use and prospective research. In situ strategies actively involve local people and might be representative samples of unaltered species and ecosystems, limiting, to some extent, the potential for environmental degradation and loss of resources. Ex situ approaches preserve genetic resources of wild and cultivated species, using a diverse body of techniques and facilities (e.g. gene banks, in vitro plant collections, field collection), providing excellent research opportunities on the components of biological diversity.

- Application for environmental remediation: Some wild species have high potential to be used in phytoremediation programs such as $N$. officinale due to their capacity to bioaccumulate environmentally toxic substances in their tissues (Torbati et al., 2014).

- Publicizing and divulgation: Drawing public attention to and promoting the potential of WEPs in restaurants and gourmet food shops, since, nowadays, there are consumers looking for food with differentiated organoleptic properties from those daily eaten.

The revival of WEPs will promote the conservation of people's local identity and traditions, since wild plants are part of the cultural heritage of the regions where they are used (Carvalho, 2010; Carvalho and Morales, 2010), increase the range of available foods and plant-based products, and diversify the agricultural productivity and small-scale and familiar agriculture. In fact, wild plants are alternative potential crops to enhance the agricultural productivity within extensive farming systems and homegardens, at a local and regional level. For instance the particular case of North-eastern Portugal, where the mountain farming which is largely based on family farming, might use the diversity of agro-ecosystems to promote diversification of crops, integration of forests non timber products and livestock activities, furthermore including sustainable gathering of wild edibles and cultivation of some wild species.

The strategies herein proposed for the valorisation of wild plant species should be carried out by a multidisciplinary team composed by farmers, agronomists, ecologists, ethnobotanists, biochemists, nutritionists, pharmacists, food engineers, chefs (for creating new dishes and recipes) and decision makers, among other stakeholders. This collaborative endeavour between different disciplines and scientists and the industrial sector will generate knowledge, new practices and relevant outputs, as well as an ecologically sustainable development.

\section{Concluding remarks}

WEPs are alternative sources of nutrients and bioactive compounds, such as vitamins ( $B_{9}, C$ and $\left.E\right)$, minerals, fiber, unsaturated fatty acids, and phenolic compounds. Their interest as contemporary foods is not only due to their nutritional value but also to their peculiar organoleptic characteristics, which makes them differentiated foods to be included in new recipes and gourmet dishes. Particular care should be taken with species containing high concentrations of oxalates and other potentially toxic compounds such as pyrrolizidine alkaloids, cucurbitacins, saponins, anthracene derivatives, monoterpenes, phenylpropanoids and prenylflavonoids. A. azurea, B. officinalis, C. ambrosioides, G. hederacea, B. dioica, T. communis, and Rumex sp.pl. are some of the species reported by EFSA as containing compounds of possible concern. Nevertheless, often the plant parts described as containing the potentially toxic compounds are not the traditionally consumed ones or are very bitter. In some cases the compounds of concern are poorly absorbed (such as saponins) or destroyed during cooking.

Given the high potential of wild harvested plants and crop wild relatives in today's society, different retrieval strategies were proposed in order to highlight their potential and promote their use in agro-food, pharmaceutical and environmental sectors. Their revival, agricultural 
production, commercialization and conservation can generate knowledge, new practices, and relevant goods and services, and contribute to an ecologically sustainable development at a local and global level.

\section{Acknowledgments}

The authors are grateful to the Foundation for Science and Technology of Portugal and FEDER, under Programme PT2020, for financial support to CIMO (UID/AGR/00690/2013). J. Pinela thanks FCT for his grant (SFRH/BD/92994/2013) funded by European Social Fund and Portuguese Ministry of Education and Science (MEC) through Programa Operacional Capital Humano (POCH).

\section{Appendix A. Supplementary data}

Supplementary data related to this article can be found at http://dx. doi.org/10.1016/j.fct.2017.10.020.

\section{Transparency document}

Transparency document related to this article can be found online at http://dx.doi.org/10.1016/j.fct.2017.10.020.

\section{References}

Abbasi, A.-R., Hajirezaei, M., Hofius, D., Sonnewald, U., Voll, L.M., 2007. Specific roles of alpha- and gamma-tocopherol in abiotic stress responses of transgenic tobacco. Plant Physiol. 143, 1720-1738.

Abdelli, M., Moghrani, H., Aboun, A., Maachi, R., 2016. Algerian Mentha pulegium L. leaves essential oil: chemical composition, antimicrobial, insecticidal and antioxidant activities. Ind. Crops Prod. 94, 197-205.

Aceituno-Mata, L., 2010. Estudio etnobotánico y agroecológico de la Sierra Norte de Madrid. Universidad Autónoma de Madrid.

Al-Qura'n, S., 2005. Ethnobotanical survey of folk toxic plants in southern part of Jordan. Toxicon 46, 119-129.

Alarcón, R., Ortiz, L.T., García, P., 2006. Nutrient and fatty acid composition of wild edible bladder campion populations [Silene vulgaris (Moench.) Garcke]. Int. J. Food Sci. Technol. 41, 1239-1242.

Amaducci, S., Pritoni, G., 1998. Effect of harvest date and cultivar on Cichorium intybus yield components in north Italy. Ind. Crops Prod. 7, 345-349.

Amalraj, A., Pius, A., 2015. Bioavailability of calcium and its absorption inhibitors in raw and cooked green leafy vegetables commonly consumed in India - an in vitro study. Food Chem. 170, 430-436.

Amirul, A.M., Juraimi, A.S., Rafii, M.Y., Hamid, A.A., Kamal Uddin, M., Alam, M.Z., Latif, M.A., 2014. Genetic improvement of Purslane (Portulaca oleracea L.) and its future prospects. Mol. Biol. Rep. 41, 7395-7411.

Anderson, I.B., Mullen, W.H., Meeker, J.E., Khojasteh-BakhtSC, Oishi, S., Nelson, S.D., Blanc, P.D., 1996. Pennyroyal toxicity: measurement of toxic metabolite levels in two cases and review of the literature. Ann. Intern. Med. 124, 726-734.

AOAC, 2016. Official Methods of Analysis of AOAC International, twentieth ed. Association of Official Analysis Chemists International. AOAC International, Gaithersburg, MD, USA.

Bacchetta, L., Visioli, F., Cappelli, G., Caruso, E., Martin, G., Nemeth, E., Bacchetta, G., Bedini, G., Wezel, A., van Asseldonk, T., van Raamsdonk, L., Mariani, F., on behalf of the Eatwild Consortium, 2016. A manifesto for the valorization of wild edible plants. J. Ethnopharmacol. 191, 180-187.

Baker, E.J., Miles, E.A., Burdge, G.C., Yaqoob, P., Calder, P.C., 2016. Metabolism and functional effects of plant-derived omega-3 fatty acids in humans. Prog. Lipid Res. 64, $30-56$.

Barreira, J.C.M., Pereira, E., Dueñas, M., Carvalho, A.M., Santos-Buelga, C., Ferreira, I.C.F.R., 2013. Bryonia dioica, Tamus communis and Lonicera periclymenum fruits: characterization in phenolic compounds and incorporation of their extracts in hydrogel formulations for topical application. Ind. Crops Prod. 49, 169-176.

Barros, L., Heleno, S. a., Carvalho, A.M., Ferreira, I.C.F.R., 2009. Systematic evaluation of the antioxidant potential of different parts of Foeniculum vulgare Mill. from Portugal. Food Chem. Toxicol. 47, 2458-2464.

Barros, L., Carvalho, A.M., Ferreira, I.C.F.R., 2010a. Leaves, flowers, immature fruits and leafy flowered stems of Malva sylvestris: a comparative study of the nutraceutical potential and composition. Food Chem. Toxicol. 48, 1466-1472.

Barros, L., Carvalho, A.M., Ferreira, I.C.F.R., 2010b. The nutritional composition of fennel (Foeniculum vulgare): shoots, leaves, stems and inflorescences. LWT - Food Sci. Technol. 43, 814-818.

Barros, L., Carvalho, A.M., Morais, J.S., Ferreira, I.C.F.R., 2010c. Strawberry-tree, blackthorn and rose fruits: detailed characterisation in nutrients and phytochemicals with antioxidant properties. Food Chem. 120, 247-254.

Barros, L., Heleno, S.A., Carvalho, A.M., Ferreira, I.C.F.R., 2010d. Lamiaceae often used in Portuguese folk medicine as a source of powerful antioxidants: vitamins and phenolics. LWT - Food Sci. Technol. 43, 544-550.
Barros, L., Oliveira, S., Carvalho, A.M., Ferreira, I.C.F.R., 2010e. In vitro antioxidant properties and characterization in nutrients and phytochemicals of six medicinal plants from the Portuguese folk medicine. Ind. Crops Prod. 32, 572-579.

Barros, L., Carvalho, A.M., Ferreira, I.C.F.R., 2011a. From famine plants to tasty and fragrant spices: three Lamiaceae of general dietary relevance in traditional cuisine of Trás-os-Montes (Portugal). LWT - Food Sci. Technol. 44, 543-548.

Barros, L., Carvalho, A.M., Ferreira, I.C.F.R., 2011b. From famine plants to tasty and fragrant spices: three Lamiaceae of general dietary relevance in traditional cuisine of Tráss-os-Montes (Portugal). LWT - Food Sci. Technol. 44, 543-548.

Barros, L., Pereira, E., Calhelha, R.C., Dueñas, M., Carvalho, A.M., Santos-Buelga, C., Ferreira, I.C.F.R., 2013. Bioactivity and chemical characterization in hydrophilic and lipophilic compounds of Chenopodium ambrosioides L. J. Funct. Foods 5, 1732-1740.

Barroso, M.R., Barros, L., Dueñas, M., Carvalho, A.M., Santos-Buelga, C., Fernandes, I.P., Barreiro, M.F., Ferreira, I.C.F.R., 2014. Exploring the antioxidant potential of Helichrysum stoechas (L.) Moench phenolic compounds for cosmetic applications: chemical characterization, microencapsulation and incorporation into a moisturizer. Ind. Crops Prod. 53, 330-336.

Bianco, V.V., Santamaria, P., Flia, A., 1998. Nutritional value and nitrate content in edible wild species used in Southern Italy. Acta Hortic. 467, 71-90.

Bicho, R.C., 2015. Regulamentação Europeia Sobre Novel Food. Identificação de plantas Silvestres Comestiveis Nacionais Como não Novo Alimento. ISA/UL, Portugal.

Brogren, M., Savage, G.P., 2003. Bioavailability of soluble oxalate from spinach eaten with and without milk products. Asia Pac. J. Clin. Nutr. 12, 219-224.

Caldas, G.F.R., Limeira, M.M.F., Araújo, A.V., Albuquerque, G.S., Silva-Neto, J. da C., Silva, T.G. da, Costa-Silva, J.H., Menezes, I.R.A. de, Costa, J.G.M. da, Wanderley, A.G., 2016. Repeated-doses and reproductive toxicity studies of the monoterpene 1,8cineole (eucalyptol) in Wistar rats. Food Chem. Toxicol. 97, 297-306.

Caleja, C., Barros, L., Antonio, A.L., Ciric, A., Soković, M., Oliveira, M.B.P.P., SantosBuelga, C., Ferreira, I.C.F.R., 2015. Foeniculum vulgare Mill. as natural conservation enhancer and health promoter by incorporation in cottage cheese. J. Funct. Foods 12, $428-438$.

Caleja, C., Barros, L., Antonio, A.L., Carocho, M., Oliveira, M.B.P.P., Ferreira, I.C.F.R., 2016a. Fortification of yogurts with different antioxidant preservatives: a comparative study between natural and synthetic additives. Food Chem. 210, 262-268.

Caleja, C., Ribeiro, A., Barros, L., Barreira, J.C.M., Antonio, A.L., Oliveira, M.Beatriz P.P., Barreiro, M.F., Ferreira, I.C.F.R., 2016b. Cottage cheeses functionalized with fennel and chamomile extracts: comparative performance between free and microencapsulated forms. Food Chem. 199, 720-726.

Carocho, M., Morales, P., Ferreira, I.C.F.R., 2015. Natural food additives: quo vadis? Trends Food Sci. Technol. 45, 284-295.

Carr, A., Frei, B., 1999. Does vitamin C act as a pro-oxidant under physiological conditions? FASEB J. 13, 1007-1024.

Carvalho, A.M., 2010. Plantas y sabiduría popular del Parque Natural de Montesinho: Un estudio etnobotánico en Portugal. Consejo Superior de Investigaciones Científicas, Madrid, España.

Carvalho, A.M., Barata, A.M., 2016. The consumption of wild edible plants. In: Ferreira, I.C.F.R., Morales, P., Barros, L. (Eds.), Wild Plants, Mushrooms and Nuts: Functional Food Properties and Applications. John Wiley \& Sons, Ltd, Chichester, UK, pp. 159-198.

Carvalho, A.M., Morales, R., 2010. Persistence of wild food and wild medicinal plant knowledge in a north-eastern region of Portugal. In: Pardo de Santayana, A.P., Puri, R. (Eds.), Ethnobotany in the New Europe: People, Health and Wild Plant Resources. Berghahn Books, Oxford, UK, pp. 147-171.

Castañeda-Álvarez, N.P., Khoury, C.K., Achicanoy, H.A., Bernau, V., Dempewolf, H. Eastwood, R.J., Guarino, L., Harker, R.H., Jarvis, A., Maxted, N., Müller, J.V., Ramirez-Villegas, J., Sosa, C.C., Struik, P.C., Vincent, H., Toll, J., 2016. Global conservation priorities for crop wild relatives. Nat. Plants 2, 16022.

Chen, J.C., Chiu, M.H., Nie, R.L., Cordell, G.A., Qiu, S.X., Lee, D.W., Kim, Y.-G., Yun, H.Y., Baek, K.J., Kwon, N.S., Takido, M., Sheldrick, G.M., Pezzuto, J.M., Kinghorn, A.D., 2005. Cucurbitacins and cucurbitane glycosides: structures and biological activities. Nat. Prod. Rep. 22, 386.

Chen, T., Mei, N., Fu, P.P., 2010. Genotoxicity of pyrrolizidine alkaloids. J. Appl. Toxicol. 30, 183-196.

Chen, X., Bao, J., Guo, J., Ding, Q., Lu, J., Huang, M., Wang, Y., 2012. Biological activities and potential molecular targets of cucurbitacins: a focus on cancer. Anticancer. Drugs 23, 777-787.

Costa, R., Rodrigues, I., Guardão, L., Rocha-Rodrigues, S., Silva, C., Magalhães, J., Ferreira-de-Almeida, M., Negrão, R., Soares, R., 2017. Xanthohumol and 8-prenylnaringenin ameliorate diabetic-related metabolic dysfunctions in mice. J. Nutr. Biochem. 45, 39-47.

Cowan, J.W., Sakr, A.H., Shadarevian, S.B., Sabry, Z.I., 1963. Composition of edible wild plants of Lebanon. J. Sci. Food Agric. 14, 484-488.

Da Rocha, M.S., Dodmane, P.R., Arnold, L.L., Pennington, K.L., Anwar, M.M., Adams, B.R., Taylor, S.V., Wermes, C., Adams, T.B., Cohen, S.M., 2012. Mode of action of pulegone on the urinary bladder of F344 rats. Toxicol. Sci. 128, 1-8.

Dias, M.I., Barros, L., Morales, P., Cámara, M., Alves, M.J., Oliveira, M.B.P.P., SantosBuelga, C., Ferreira, I.C.F.R., Ferreira, I.C.F.R., Sarmento-Ribeiro, A.B., Girão, H., Cruz, M.T., Batista, M.T., 2016. Wild Fragaria vesca L. fruits: a rich source of bioactive phytochemicals. Food Funct. 7, 4523-4532.

Dodson, C.D., Stermitz, F.R., 1986. Pyrrolizidine alkaloids from borage (Borago officinalis) seeds and flowers. J. Nat. Prod. 49, 727-728.

EFSA, 2009. EFSA Compendium of botanicals that have been reported to contain toxic, addictive, psychotropic or other substances of concern. EFSA J. 2009 (7), 281.

EFSA, 2011. Scientific opinion on pyrrolizidine alkaloids in food and feed. EFSA J. 9 (11), 2406.

EFSA, 2012. Compendium of botanicals reported to contain naturally occuring substances 
of possible concern for human health when used in food and food supplements. EFSA J. 10, 2663.

EMA, 2014. Public Statement on the Use of Herbal Medicinal Products Containing Toxic, Unsaturated Pyrrolizidine Alkaloids (PAs).

EMA, 2016. Public Statement on the Use of Herbal Medicinal Products Containing Pulegone and Menthofuran.

European Commission, 2016. Communication from the Commission to the European Parliamente, the Council, the European Economic and Social Committe and the Committe of the Regions. Next Steps for a Sustainable European Future. European Action for Sustainability. European Commission, Strasbourg.

Fajardo, V., Alonso-Aperte, E., Varela-Moreiras, G., 2015. Folate content in fresh-cut vegetable packed products by 96 -well microtiter plate microbiological assay. Food Chem. 169, 283-288.

Fernandes, Â.S.F., Barros, L., Carvalho, A.M., Ferreira, I.C.F.R., 2010. Lipophilic and hydrophilic antioxidants, lipid peroxidation inhibition and radical scavenging ac tivity of two Lamiaceae food plants. Eur. J. Lipid Sci. Technol. 112, 1115-1121.

Galli, F., Azzi, A., Birringer, M., Cook-Mills, J.M., Eggersdorfer, M., Frank, J., Cruciani, G. Lorkowski, S., Özer, N.K., 2017. Vitamin E: emerging aspects and new directions. Free Radic. Biol. Med. 102, 16-36.

García Herrera, P., 2014. Plantas silvestres de consumo tradicional en España: Caracterización de su valor nutricional y estimación de su actividad antifúngica. Facultad de Farmacia - Universidad Complutense de Madrid.

García-Herrera, P., Morales, P., Fernández-Ruiz, V., Sánchez-Mata, M.C., Cámara, M. Carvalho, A.M., Ferreira, I.C.F.R., Molina, M., Tardío, J., 2013. Evaluación nutricional y de la actividad biológica de los bulbos silvestres de Allium ampeloprasum L. Madrid.

García-Herrera, P., Morales, P., Fernández-Ruiz, V., Sánchez-Mata, M.C., Cámara, M., Carvalho, a. M., Ferreira, I.C.F.R., Pardo-de-Santayana, M., Molina, M., Tardio, J., 2014a. Nutrients, phytochemicals and antioxidant activity in wild populations of Allium ampeloprasum L., a valuable underutilized vegetable. Food Res. Int. 62, 272-279.

García-Herrera, P., Sánchez-Mata, M.C., Cámara, M., Fernández-Ruiz, V., Díez-Marqués, C., Molina, M., Tardío, J., 2014b. Nutrient composition of six wild edible Mediterranean Asteraceae plants of dietary interest. J. Food Compos. Anal. 34, 163-170.

García-Jiménez, N., Péerez-Alonso, M.J., Velasco-Negueruela, A., 2000. Chemical composition of fennel iil, Foeniculum vulgare Miller, from Spain. J. Essent. Oil Res. 12, 159-162.

Gille, L., Monzote, L., Stamberg, W., Staniek, K., 2010. Toxicity of ascaridole from Chenopodium ambrosioides in mammalian mitochondria. BMC Pharmacol. 10, A10.

Glensk, M., Wray, V., Nimtz, M., Schöpke, T., 1998. Silenosides A-c, Triterpenoid Saponins from Silene Vulgaris. https://doi.org/10.1021/np980505r.

Gry, J., Søborg, I., Andersson, H.C., 2006. Cucurbitacins in Plant Food, TemaNord. Nordic Council of Ministers, Copenhagen.

Guerra, L., Pereira, C., Andrade, P.B., Rodrigues, M.Â., Ferreres, F., De Pinho, P.G. Seabra, R.M., Valentão, P., 2008. Targeted metabolite analysis and antioxidant potential of Rumex induratus. J. Agric. Food Chem. 56, 8184-8194.

Guil, J.L., Torija, M.E., Giménez, J.J., Rodríguez-García, I., Giménez, A., 1996. Oxalic acid and calcium determination in wild edible plants. J. Agric. Food Chem. 44 , 1821-1823.

Guil-Guerrero, J.L., Giménez-Giménez, A., Rodríguez-Garcia, I., Torija-Isasa, M.E., 1998. Nutritional composition of Sonchus species (S. asper L., S. oleraceus L. and S. tenerrimus L.). J. Sci. Food Agric. 76, 628-632.

Guil-Guerrero, J.L., Madrid, P.C., Isasa, M.E.T., 1999. Mineral elements determination in wild edible plants. Ecol. Food Nutr. 38, 209-222.

Guil-Guerrero, J.L., Rincón-Cervera, M.Á., Gómez-Mercado, F., Ramos-Bueno, R.P., Venegas-Venegas, E., 2013. New seed oils of Boraginaceae rich in stearidonic and gamma-linolenic acids from the Maghreb region. J. Food Compos. Anal. http://dx. doi.org/10.1016/j.jfca.2013.02.007.

Guimarães, R., Calhelha, R.C., Froufe, H.J.C., Abreu, R.M.V., Carvalho, A.M., Queiroz Maria João, R.P., Ferreira, I.C.F.R., Cao, P., Queiroz, M.J.R.P., 2016. Wild Roman chamomile extracts and phenolic compounds: enzymatic assays and molecular modelling studies with VEGFR-2 tyrosine kinase. Food Funct. 7, 79-83.

Gupta, U.C., Gupta, S.C., 2014. Sources and deficiency diseases of mineral nutrients in human health and nutrition: a review. Pedosphere 24, 13-38.

Güçlü-Üstündağ, Ö., Mazza, G., 2007. Saponins: properties, applications and processing. Crit. Rev. Food Sci. Nutr. 47, 231-258.

Hylands, P.J., Mansour, E.-S.S., 1982. A revision of the structure of cucurbitacin S from Bryonia dioica. Phytochemistry 21, 2703-2707.

Hylands, P.J., Salama, A.M., 1976. Cucurbitacin S, a new cucurbitacin from Bryonia dioica. Phytochemistry 15, 559-560.

Kaur, N., Chugh, V., Gupta, A.K., 2014. Essential fatty acids as functional components of foods: a review. J. Food Sci. Technol. 51, 2289-2303.

Kaushik, U., Aeri, V., Mir, S.R., 2015. Cucurbitacins - an insight into medicinal leads from nature. Pharmacogn. Rev. 9, 12-18.

Kemal, Y., Günayd, J., Dündar, Z.D., Çekmen, B., Belgin, N., Ak, J., Köylü, R., Cander, B.G., 2015. Case report intoxication due to Papaver rhoeas (corn poppy ): five case reports. Case Rep. Med. 2015.

Kim, K., Friso, S., Choi, S.-W., 2009. DNA methylation, an epigenetic mechanism connecting folate to healthy embryonic development and aging. J. Nutr. Biochem. 20, 917-926.

Kiuchi, F., Itano, Y., Uchiyama, N., Honda, G., Tsubouchi, A., Nakajima-Shimada, J., Aoki, T., 2002. Monoterpene hydroperoxides with trypanocidal activity from Chenopodium ambrosioides. J. Nat. Prod. 65, 509-512.

Kovács, A., Forgo, P., Zupkó, I., Réthy, B., Falkay, G., Szabó, P., Hohmann, J., 2007. Phenanthrenes and a dihydrophenanthrene from Tamus communis and their cytotoxic activity. Phytochemistry 68, 687-691.

Kovács, A., Vasas, A., Hohmann, J., 2008. Natural phenanthrenes and their biological activity. Phytochemistry 69, 1084-1110.

Kristanc, L., Kreft, S., 2016a. European medicinal and edible plants associated with subacute and chronic toxicity part II: plants with hepato-, neuro-, nephro- and immunotoxic effects. Food Chem. Toxicol. 92, 38-49.

Kristanc, L., Kreft, S., 2016b. European medicinal and edible plants associated with subacute and chronic toxicity part I: plants with carcinogenic, teratogenic and endocrine-disrupting effects. Food Chem. Toxicol. 92, 150-164.

Kumarasamy, Y., Cox, P.J., Jaspars, M., Nahar, L., Sarker, S.D., 2003. Isolation, structure elucidation and biological activity of hederacine $\mathrm{A}$ and $\mathrm{B}$, two unique alkaloids from Glechoma hederaceae. Tetrahedron 59, 6403-6407.

Lee, J., Koo, N., Min, D.B., 2004. Reactive oxygen species, aging, and antioxidative nutraceuticals. Compr. Rev. Food Sci. Food Saf. 3, 21-33.

Li, K., Tang, Y., Fawcett, J., Gu, J., Zhong, D., 2005. Characterization of the pharmacokinetics of dioscin in rat. Steroids 70, 525-530.

Liebman, M., Al-Wahsh, I.A., 2011. Probiotics and other key determinants of dietary oxalate absorption. Adv. Nutr. 2, 254-260.

Magos Brehm, J., Maxted, N., Ford-Lloyd, B.V., Martins-Loução, M.A., 2008. National inventories of crop wild relatives and wild harvested plants: case-study for Portugal. Genet. Resour. Crop Evol. 55, 779-796.

Marostica, L.L., de Barros, A.L.B., Oliveira, J., Salgado, B.S., Cassali, G.D., Leite, E.A., Cardoso, V.N., Lang, K.L., Caro, M.S.B., Durán, F.J., Schenkel, E.P., de Oliveira, M.C., Simões, C.M.O., 2017. Antitumor effectiveness of a combined therapy with a new cucurbitacin B derivative and paclitaxel on a human lung cancer xenograft model. Toxicol. Appl. Pharmacol. 329, 272-281.

Martins, D., Barros, L., Carvalho, A.M., Ferreira, I.C.F.R., 2011. Nutritional and in vitro antioxidant properties of edible wild greens in Iberian Peninsula traditional diet. Food Chem. 125, 488-494.

Martins, A., Barros, L., Carvalho, A.M., Santos-Buelga, C., Fernandes, I.P., Barreiro, F. Ferreira, I.C.F.R., 2014. Phenolic extracts of Rubus ulmifolius Schott flowers: characterization, microencapsulation and incorporation into yogurts as nutraceutical sources. Food Funct. 5, 1091-1100.

Martins, N., Roriz, C.L., Morales, P., Barros, L., Ferreira, I.C.F.R., 2016. Food colorants: challenges, opportunities and current desires of agro-industries to ensure consumer expectations and regulatory practices. Trends Food Sci. Technol. 52.

Mason, J.B., Tang, S.Y., 2016. Folate status and colorectal cancer risk: a 2016 update. Mol. Asp. Med. http://dx.doi.org/10.1016/j.mam.2016.11.010.

Maxted, N., Ford-Lloyd, B.V., Jury, S., Kell, S., Scholten, M., 2006. Towards a definition of a crop wild relative. Biodivers. Conserv. 15, 2673-2685.

Menendez-Baceta, G., Aceituno-Mata, L., Tardío, J., Reyes-García, V., Pardo-deSantayana, M., 2012. Wild edible plants traditionally gathered in gorbeialdea (biscay, basque country). Genet. Resour. Crop Evol. 59, 1329-1347.

Menendez-Baceta, G., Pardo-de-Santayana, M., Aceituno-Mata, L., Tardío, J., ReyesGarcía, V., 2017. Trends in wild food plants uses in Gorbeialdea (Basque Country). Appetite 112, 9-16.

Molina, M., Pardo-de-Santayana, M., Tardío, J., 2016. Natural production and cultivation of mediterranean wild edibles. In: Mediterranean Wild Edible Plants. Springer New York, New York, NY, pp. 81-107.

Monzote, L., Stamberg, W., Staniek, K., Gille, L., 2009. Toxic effects of carvacrol, caryophyllene oxide, and ascaridole from essential oil of Chenopodium ambrosioides on mitochondria. Toxicol. Appl. Pharmacol. 240, 337-347.

Morales, P., 2011. Vegetales silvestres de uso alimentario: Determinación de compuestos bioactivos y valoración de la capacidad antioxidante. Universidad Complutense de Madrid, Facultad de Farmacia.

Morales, P., Carvalho, A.M., Sánchez-Mata, M.C., Cámara, M., Molina, M., Ferreira, I.C.F.R., 2012a. Tocopherol composition and antioxidant activity of Spanish wild vegetables. Genet. Resour. Crop Evol. 59, 851-863.

Morales, P., Ferreira, I.C.F.R., Carvalho, A.M., Sanchez-Mata, M., Camara, M., Tardio, J., 2012b. Fatty acids profiles of some Spanish wild vegetables. Food Sci. Technol. Int. 18, 281-290.

Morales, P., Ferreira, I.C.F.R., Carvalho, A.M., Fernández-Ruiz, V., Sánchez-Mata, M.C., Cámara, M., Morales, R., Tardío, J., 2013. Wild edible fruits as a potential source of phytochemicals with capacity to inhibit lipid peroxidation. Eur. J. Lipid Sci. Technol. 115, 176-185.

Morales, P., Ferreira, I.C.F.R., Carvalho, A.M., Sánchez-Mata, M.C., Cámara, M., Fernández-Ruiz, V., Pardo-de-Santayana, M., Tardío, J., 2014. Mediterranean noncultivated vegetables as dietary sources of compounds with antioxidant and biological activity. LWT - Food Sci. Technol. 55, 389-396.

Morales, P., Fernández-Ruiz, V., Sánchez-Mata, M.C., Cámara, M., Tardío, J., 2015. Optimization and application of FL-HPLC for folates analysis in 20 species of mediterranean wild vegetables. Food Anal. Methods 8, 302-311.

Muñoz, S.M., Salvarelli, S.M., Isabel Saiz, M., Conde, F.P., 1992. A toxic protein from Bryonia dioica Jacq. fruits: the brydiofin. Biochem. Biophys. Res. Commun. 183 1011-1018.

Muzquiz, M., Varela, A., Burbano, C., Cuadrado, C., Guillamón, E., Pedrosa, M.M., 2012. Bioactive compounds in legumes: pronutritive and antinutritive actions. Implications for nutrition and health. Phytochem. Rev. 11, 227-244.

Niki, E., 2014. Role of vitamin E as a lipid-soluble peroxyl radical scavenger: in vitro and in vivo evidence. Free Radic. Biol. Med. 66, 3-12.

Niki, E., Noguchi, N., Tsuchihashi, H., Gotoh, N., 1995. Interaction among vitamin C, vitamin $\mathrm{E}$ and $\beta$-carotene. Am. J. Clin. Nutr. 62, 1322S-1326S.

Nikolić, M., Glamočlija, J., Ferreira, I.C.F.R., Calhelha, R.C., Fernandes, Â., Marković, T., Marković, D., Giweli, A., Soković, M., 2014. Chemical composition, antimicrobial, antioxidant and antitumor activity of Thymus serpyllum L., Thymus algeriensis Boiss. and Reut and Thymus vulgaris L. essential oils. Ind. Crops Prod. 52, 183-190. 
Oda, K., Matsuda, H., Murakami, T., Katayama, S., Ohgitani, T., Yoshikawa, M., 2000. Adjuvant and haemolytic activities of 47 saponins derived from medicinal and food plants. Biol. Chem. 381, 67-74.

Oliveira, I., Valentão, P., Lopes, R., Andrade, P.B., Bento, A., Pereira, J.A., 2009. Phytochemical characterization and radical scavenging activity of Portulaca oleraceae L. leaves and stems. Microchem. J. 92, 129-134.

Oobayashi, K., Yoshikawa, K., Arihara, S., 1992. Structural revision of bryonoside and structure elucidation of minor saponins from Bryonia dioica. Phytochemistry 31, 943-946.

Ottaway, B.P., 2010. Stability of vitamins during food processing and storage. In: Skibsted, L.H., Risbo, J., Andersen, M.L. (Eds.), Chemical Deterioration and Physical Instability of Food and Beverages. Woodhead Publishing, pp. 539-560.

Otten, J.J., Hellwig, J.P., Meyers, L.D., 2006. Dietary Reference Intakes: the Essential Guide to Nutrient Requirements. The National Academies Press, Washington, D.C.

Palaniswamy, U.R., Bible, B., Mcavoy, R.J., 2004. Oxalic acid concentrations in purslane (Portulaca oleraceae L.) is altered by the stage of harvest and the nitrate to ammonium ratios in hydroponics. Sci. Hortic. Amst. 102, 267-275.

Pandey, K.B., Rizvi, S.I., 2009. Plant polyphenols as dietary antioxidants in human health and disease. Oxid. Med. Cell Longev. 2, 270-278.

Pardo-de-Santayana, M., Tardío, J., Blanco, E., Carvalho, A.M., Lastra, J.J., Miguel, E.S., Morales, R., 2007. Traditional knowledge of wild edible plants used in the northwest of the Iberian Peninsula (Spain and Portugal): a comparative study. J. Ethnopharmacol. 27, 1-11.

Pereira, C., Barros, L., Carvalho, A.M., Ferreira, I.C.F.R., 2011. Nutritional composition and bioactive properties of commonly consumed wild greens: potential sources for new trends in modern diets. Food Res. Int. 44, 2634-2640.

Pereira, C., Barros, L., Carvalho, A.M., Ferreira, I.C.F.R., 2013. Use of UFLC-PDA for the analysis of organic acids in thirty-five species of food and medicinal plants. Food Anal. Methods 6, 1337-1344.

Pereira, J., Lopes-Rodrigues, V., Xavier, C., Lima, M., Lima, R., Ferreira, I., Vasconcelos, M., 2016. An aqueous extract of Tuberaria lignosa inhibits cell growth, alters the cell cycle profile, and induces apoptosis of NCI-H460 tumor cells. Molecules 21, 595.

Petropoulos, S.A., Karkanis, A., Fernandes, Â., Barros, L., Ferreira, I.C.F.R., Ntatsi, G., Petrotos, K., Lykas, C., Khah, E., 2015. Chemical composition and yield of six genotypes of common purslane (Portulaca oleracea L.): an alternative source of omega-3 fatty acids. Plant Foods Hum. Nutr. 70, 420-426.

Petropoulos, S., Karkanis, A., Martins, N., Ferreira, I.C.F.R., 2016. Phytochemical composition and bioactive compounds of common purslane (Portulaca oleracea L.) as affected by crop management practices. Trends Food Sci. Technol. 55, 1-10.

Pinela, J., Barros, L., Carvalho, A.M., Ferreira, I.C.F.R., 2011. Influence of the drying method in the antioxidant potential and chemical composition of four shrubby flowering plants from the tribe Genisteae (Fabaceae). Food Chem. Toxicol. 49, 2983-2989.

Pinela, J., Barreira, J.C.M., Barros, L., Antonio, A.L., Carvalho, A.M., Oliveira, M.B.P.P., Ferreira, I.C.F.R., 2016a. Postharvest quality changes in fresh-cut watercress stored under conventional and inert gas-enriched modified atmosphere packaging. Postharvest Biol. Technol. 112, 55-63.

Pinela, J., Barreira, J.C.M., Barros, L., Cabo Verde, S., Antonio, A.L., Carvalho, A.M., Oliveira, M.B.P.P., Ferreira, I.C.F.R., 2016b. Suitability of gamma irradiation for preserving fresh-cut watercress quality during cold storage. Food Chem. 206, 50-58.

Pinela, J., Barreira, J.C.M., Barros, L., Cabo Verde, S., Antonio, A.L., Oliveira, M.B.P.P., Carvalho, A.M., Ferreira, I.C.F.R., 2016c. Modified atmosphere packaging and postpackaging irradiation of Rumex induratus leaves: a comparative study of postharvest quality changes. J. Food Sci. Technol. 53, 2943-2956.

Pinela, J., Barros, L., Antonio, A.L., Carvalho, A., Oliveira, M.B.P.P., Ferreira, I.C.F.R., 2016d. Quality control of gamma irradiated dwarf mallow (Malva neglecta Wallr.) based on color, organic acids, total phenolics and antioxidant parameters. Molecules $21,467$.

Pinela, J., Carocho, M., Dias, M.I., Caleja, C., Barros, L., Ferreira, I.C.F.R., 2016e. Wild plant-based functional foods, drugs, and nutraceuticals. In: Ferreira, I.C.F.R. Morales, P., Barros, L. (Eds.), Wild Plants, Mushrooms and Nuts. John Wiley \& Sons, Ltd, Chichester, UK, pp. 315-351.

Pinela, J., Prieto, M.A., Antonio, A.L., Carvalho, A.M., Oliveira, M.B.P.P., Barros, L. Ferreira, I.C.F.R., 2017a. Ellagitannin-rich bioactive extracts of Tuberaria lignosa: insights into the radiation-induced effects in the recovery of high added-value compounds. Food Funct. 8.

Pinela, J., Prieto, M.A., Barreiro, M.F., Carvalho, A.M., Oliveira, M.B.P.P., Curran, T.P., Ferreira, I.C.F.R., 2017b. Valorisation of tomato wastes for development of nutrientrich antioxidant ingredients: a sustainable approach towards the needs of the today's society. Innov. Food Sci. Emerg. Technol. 41, 160-171.

Podolak, I., Galanty, A., Sobolewska, D., 2010. Saponins as cytotoxic agents: a review. Phytochem. Rev. 9, 425-474.

Pohlmann, J., 1975. Die cucurbitacine in Bryonia alba und Bryonia dioica. Phytochemistry 14, 1587-1589.

Quintaes, K.D., Diez-Garcia, R.W., 2015. The importance of minerals in the human diet. In: Handbook of Mineral Elements in Food. John Wiley \& Sons, Ltd, Chichester, UK, pp. 1-21.

Radulović, N.S., Genčić, M.S., Stojanović, N.M., Randjelović, P.J., Stojanović-Radić, Z.Z., Stojiljković, N.I., 2017. Toxic essential oils. Part V: behaviour modulating and toxic properties of thujones and thujone-containing essential oils of Salvia officinalis L. Artemisia absinthium L., Thuja occidentalis L. and Tanacetum vulgare L. Food Chem. Toxicol. 105, 355-369.

Ranfa, A., Maurizi, A., Romano, B., Bodesmo, M., 2014. The importance of traditional uses and nutraceutical aspects of some edible wild plants in human nutrition: the case of Umbria (central Italy). Plant Biosyst. 148, 297-306.

Regulation (EU) No 1169/2011 of the European Parliament and of the Council of 25
October 2011 on the provision of food information to consumers, amending Regulations (EC) No 1924/2006 and (EC) No 1925/2006 of the European Parliament and of the Council, and repealing Commission Directive 87/250/EEC, Council Directive 90/496/EEC, Commission Directive 1999/10/EC, Directive 2000/13/EC of the European Parliament and of the Council, Commission Directives 2002/67/EC and 2008/5/EC and Commission regulation (EC) No 608/2004. Off. J. Eur. Union. 54, 18-63.

Renna, M., Cocozza, C., Gonnella, M., Abdelrahman, H., Santamaria, P., 2015. Elemental characterization of wild edible plants from countryside and urban areas. Food Chem. 177, 29-36.

Réthy, B., Kovács, A., Zupkó, I., Forgo, P., Vasas, A., Falkay, G., Hohmann, J., 2006. Cytotoxic phenanthrenes from the rhizomes of Tamus communis. Planta Med. 72, 767-770.

Reyes-García, V., Menendez-Baceta, G., Aceituno-Mata, L., Acosta-Naranjo, R., CalvetMir, L., Domínguez, P., Garnatje, T., Gómez-Baggethun, E., Molina-Bustamante, M., Molina, M., Rodríguez-Franco, R., Serrasolses, G., Vallès, J., Pardo-De-Santayana, M., 2015. From famine foods to delicatessen: interpreting trends in the use of wild edible plants through cultural ecosystem services. Ecol. Econ. 120, 303-311.

Roeder, E., 1999. Analysis of pyrrolizidine alkaloids. Curr. Org. Chem. 3, 557-576.

Saini, R.K., Nile, S.H., Keum, Y.S., 2016. Folates: Chemistry, analysis, occurrence, biofortification and bioavailability. Food Res. Int. 89, 1-13.

Sánchez-Mata, M. de C., Tardío, J. (Eds.), 2016. Mediterranean Wild Edible Plants: Ethnobotany and Food Composition Tables. Springer Science, Spain.

Sánchez-Mata, M.C., Loera, R.D.C., Morales, P., Fernández-Ruiz, V., Cámara, M., Marqués, C.D., Pardo-de-Santayana, M., Tardío, J., 2012. Wild vegetables of the Mediterranean area as valuable sources of bioactive compounds. Genet. Resour. Crop Evol. 59, 431-443.

Sánchez-Mata, M. de C., Matallana-González, M.C., Morales, P., 2016. The contribution of wild plants to dietary intakes of micronutrients (I): vitamins. In: Sánchez-Mata, M. de C., Tardío, J. (Eds.), Mediterranean Wild Edible Plants: Ethnobotany and Food Composition Tables. Springer New York, New York, NY, pp. 111-139.

Schippmann, U., Cunningham, A.B., Leaman, D.J., 2002. Impact of Cultivation and Gathering of Medicinal Plants on Biodiversity: Global Trends and Issues, in: Biodiversity and the Ecosystem Approach in Agriculture, Forestry and Fisheries. FAO, Rome.

Simopoulos, A.P., 2002. The importance of the ratio of omega-6/omega-3 essential fatty acids. Biomed. Pharmacother. 56, 365-379.

Sinha, S., Khan, S., Shukla, S., Lakra, A.D., Kumar, S., Das, G., Maurya, R., Meeran, S.M., 2016. Cucurbitacin B inhibits breast cancer metastasis and angiogenesis through VEGF-mediated suppression of FAK/MMP-9 signaling axis. Int. J. Biochem. Cell Biol. $77,41-56$.

Smith, L.W., Culvenor, C.C.J., 1981. Plant sources of hepatotoxic pyrrolizidine alkaloids. J. Nat. Prod. 44, 129-152.

Smolarz, H.D., Wegiera, M., Wianowska, D., Dawidowicz, A.L., 2011. Anthracene derivatlves in some species of Rumex L genus. Acta Soc. Bot. Pol. 76, 103-108.

Smolin, L.A., Grosvenor, M.B., 2013. Nutrition: Science and Applications, third ed. Wiley.

Souci, S.W., Siegfried, W., Fachmann, W., Kraut, H., Kirchhoff, E., Germany. Bundesministerium für Verbraucherschutz, E. und L., Deutsche Forschungsanstalt für Lebensmittelchemie, 2008. Food Composition and Nutrition Tables, seventh ed. MedPharm Scientific Publishers.

Sõukand, R., 2016. Perceived reasons for changes in the use of wild food plants in Saaremaa, Estonia. Appetite 107, 231-241.

Sõukand, R., Quave, C.L., Pieroni, A., Pardo-de-Santayana, M., Tardío, J., Kalle, R., £uczaj, £., Svanberg, I., Kolosova, V., Aceituno-Mata, L., Menendez-Baceta, G., Kołodziejska-Degórska, I., Pirożnikow, E., Petkevièius, R., Hajdari, A., Mustafa, B., 2013. Plants used for making recreational tea in Europe: a review based on specific research sites. J. Ethnobiol. Ethnomed. 9, 58.

Stein, A.J., 2010. Global impacts of human mineral malnutrition. Plant Soil 335, 133-154.

Street, R.A., Sidana, J., Prinsloo, G., Prinsloo, G., 2013. Cichorium intybus: traditional uses, phytochemistry, pharmacology, and toxicology. Evid. Based. Complement. Altern. Med. 2013, 579319.

Swaminathan, R., 2003. Magnesium metabolism and its disorders. Clin. Biochem. Rev. 24, 47-66.

Tardío, J., 2005. Spring is coming: the gathering and consumption of wild vegetables in Spain. In: Pardo-de-Santayana, M., Pieroni, A., Puri, R.K. (Eds.), Ethnobotany in the New Europe: People, Health and Wild Plant Resources. Berghahn Books, pp. 211-238.

Tardio, J., Pascual, H., Morales, R., 2002. Alimentos silvestres de Madrid: Guía de plantas y setas de uso alimentario tradicional en la Comunidad de Madrid. Ediciones La Librería, Madrid, España.

Tardío, J., Pardo-de-Santayana, M., Morales, R., 2006. Ethnobotanical review of wild edible plants in Spain. Bot. J. Linn. Soc. 152, 27-71.

Tardío, J., Molina, M., Aceituno-Mata, L., Pardo-de-Santayana, M., Morales, R., Fernández-Ruiz, V., Morales, P., García, P., Cámara, M., Sánchez-Mata, M.C., 2011. Montia fontana L. (Portulacaceae), an interesting wild vegetable traditionally consumed in the Iberian Peninsula. Genet. Resour. Crop Evol. 58, 1105-1118.

Tardío, J., Sánchez-Mata, M. de C., Morales, R., Molina, M., García-Herrera, P., Morales, P., Díez-Marqués, C., Fernández-Ruiz, V., Cámara, M., Pardo-de-Santayana, M., Matallana-González, M.C., Ruiz-Rodríguez, B.M., Sánchez-Mata, D., Torija-Isasa, M.E., Guil-Guerrero, J.L., Boussalah, N., 2016. Ethnobotanical and food composition monographs of selected mediterranean wild edible plants. In: Sánchez-Mata, M. de C., Tardío, J. (Eds.), Mediterranean Wild Edible Plants. Springer, pp. 273-470.

Teixeira, B., Marques, A., Ramos, C., Batista, I., Serrano, C., Matos, O., Neng, N.R., Nogueira, J.M.F., Saraiva, J.A., Nunes, M.L., 2012. European pennyroyal (Mentha pulegium) from Portugal: chemical composition of essential oil and antioxidant and 
antimicrobial properties of extracts and essential oil. Ind. Crops Prod. 36, 81-87.

The European Parliment and the Council of the European Union, 2011. L 304/18, Official Journal of the European Union.

The Plant List, 2013. Version 1.1. Published on the Internet [WWW Document]. URL. http://www.theplantlist.org/, Accessed date: 31 July 2017.

Thomassen, D., Knebel, N., Slattery, J.T., McClanahan, R.H., Nelson, S.D., 1992. Reactive intermediates in the oxidation of menthofuran by cytochromes P-450. Chem. Res. Toxicol. 5, 123-130.

Torbati, S., Khataee, A., Movafeghi, A., 2014. Application of watercress (Nasturtium officinale $\mathrm{R}$. Br.) for biotreatment of a textile dye: investigation of some physiological responses and effects of operational parameters. Chem. Eng. Res. Des. 92, 1934-1941.

Torija-Isasa, M.E., Matallana-González, M.C., 2016. A historical perspective of wild plant foods in the mediterranean area. In: Mediterranean Wild Edible Plants. Springer New York, New York, NY, pp. 3-13.

Trichopoulou, a., Vasilopoulou, E., Hollman, P., Chamalides, C., Foufa, E., Kaloudis, T., Kromhout, D., Miskaki, P., Petrochilou, I., Poulima, E., Stafilakis, K., Theophilou, D., 2000. Nutritional composition and flavonoid content of edible wild greens and green pies: a potential rich source of antioxidant nutrients in the Mediterranean diet. Food Chem. 70, 319-323.

Tucker, A.O., Maciarello, M.J., 1998. Some toxic culinary herbs in North America. Dev. Food Sci. 40, 401-414.

Turner, N.J., Łuczaj, Ł.J., Migliorini, P., Pieroni, A., Dreon, A.L., Sacchetti, L.E., Paoletti, M.G., 2011. Edible and tended wild plants, traditional ecological knowledge anc agroecology. CRC. Crit. Rev. Plant Sci. 30, 198-225.

Tuttolomondo, T., Licata, M., Leto, C., Bonsangue, G., Letizia Gargano, M., Venturella, G., La Bella, S., 2014. Popular uses of wild plant species for medicinal purposes in the Nebrodi Regional Park (North-Eastern Sicily, Italy). J. Ethnopharmacol. 157, 21-37.

Vacillotto, G., Favretto, D., Seraglia, R., Pagiotti, R., Traldi, P., Mattoli, L., 2013. A rapid and highly specific method to evaluate the presence of pyrrolizidine alkaloids in Borago officinalis seed oil. J. Mass Spectrom. 48, 1078-1082.

Vasquez, K.R. de, 2016. Foraged food trend is part epicurean, part environmental [WWW Document]. Food Nutr. Mag URL. https://foodandnutrition.org/july-august-2016/ foraged-food-trend-part-epicurean-part-environmental/, Accessed date: 24 August 2017.

Vermerris, W., Nicholson, R., 2008a. Families of phenolic compounds and means of classification. In: Phenolic Compound Biochemistry. Springer Netherlands, Dordrecht, pp. 1-34.

Vermerris, W., Nicholson, R., 2008b. Phenolic compounds and their effects on human health. In: Vermerris, W., Nicholson, R. (Eds.), Phenolic Compound Biochemistry. Springer Netherlands, Dordrecht, pp. 235-255.

Vinha, A.F., Alves, R.C., Barreira, S.V.P., Costa, A.S.G., Oliveira, M.B.P.P., 2015. Impact of boiling on phytochemicals and antioxidant activity of green vegetables consumed in the Mediterranean diet. Food Funct. 6, 1157-1163.

Vizgirdas, R.S., Rey-Vizgirdas, E.M., 2006. Wild Plants of the Sierra Nevada. Univdersity of Nevada Press, Reno, Nevada.

Wiedenfeld, H., 2011. Plants containing pyrrolizidine alkaloids: toxicity and problems. Food Addit. Contam. Part A 28, 282-292.

Wretensjö, I., Karlberg, B., 2003. Pyrrolizidine alkaloid content in crude and processed borage oil from different processing stages. J. Am. Oil Chem. Soc. 80, 963-970.

Wu, S., Xu, H., Peng, J., Wang, C., Jin, Y., Liu, K., Sun, H., Oin, J., 2015. Potent antiinflammatory effect of dioscin mediated by suppression of TNF- $\alpha$-induced VCAM-1, ICAM-1and EL expression via the NF-кB pathway. Biochimie 110, 62-72.

Zhang, G., Zeng, X., Zhang, R., Liu, J., Zhang, W., Zhao, Y., Zhang, X., Wu, Z., Tan, Y., Wu, Y., Du, B., 2016. Dioscin suppresses hepatocellular carcinoma tumor growth by inducing apoptosis and regulation of TP53, BAX, BCL2 and cleaved CASP3. Phytomedicine 23, 1329-1336.

Zhang, H., Mittal, N., Leamy, L.J., Barazani, O., Song, B.-H., 2017. Back into the wild apply untapped genetic diversity of wild relatives for crop improvement. Evol. Appl. $10,5-24$.

Zhao, X., Xu, L., Zheng, L., Yin, L., Qi, Y., Han, X., Xu, Y., Peng, J., 2016. Potent effects of dioscin against gastric cancer in vitro and in vivo. Phytomedicine 23, 274-282.

Żołnierczyk, A.K., Mączka, W.K., Grabarczyk, M., Wińska, K., Woźniak, E., Anioł, M., 2015. Isoxanthohumol - biologically active hop flavonoid. Fitoterapia 103, 71-82.

Łuczaj, Ł., 2010. Changes in the utilization of wild green vegetables in Poland since the 19th century: a comparison of four ethnobotanical surveys. J. Ethnopharmacol. 128, 395-404.

Łuczaj, Ł., Pieroni, A., Tardío, J., Pardo-de-Santayana, M., Sõukand, R., Svanberg, I., Kalle, R., 2012. Wild food plant use in 21st century Europe: the disappearance of old traditions and the search for new cuisines involving wild edibles. Acta Soc. Bot. Pol $81,359-370$ 